\title{
Associations between morphological awareness and literacy skills in German primary school children: the roles of grade level, phonological processing and vocabulary
}

\author{
Astrid Haase $^{1,2}\left(\mathbb{0} \cdot\right.$ Claudia Steinbrink $^{1}[0$
}

Accepted: 22 December 2021 / Published online: 10 February 2022

(c) The Author(s) 2022

\begin{abstract}
Studies investigating relations between morphological awareness and literacy in German, a language with a rather transparent but asymmetric orthography, are sparse. Little is known about the role of grade level for these relationships and of their relative strength compared to those between other language-related variables and literacy skills. This cross-sectional study was conducted with German-speaking second-, third- and fourth-graders ( $n$ of final sample $\geq 85$ per grade). Morphological awareness tasks required the production of inflections, derivations and compounds. Additionally, phonological processing, vocabulary, reading fluency, reading comprehension and spelling were measured. Factor analyses revealed two facets of morphological awareness: morphological fluency and morphological awareness for pseudowords. These were correlated with both reading and spelling skills in all grades. More literacy variables were related to morphological fluency in Grade 4 than in Grades 2 and 3. In regression analyses, variance in literacy skills was predominantly explained by phonological awareness. Morphological awareness did not explain additional variance. The results reveal that different facets of morphological awareness are related to literacy skills in German primary school children. Despite the asymmetry of German orthography, no evidence was found for differences in the association of morphological awareness with spelling versus reading. Phonological processing shows stronger relations with literacy than morphological awareness does. This might indicate that in the transparent German orthography, alphabetic reading and spelling strategies are particularly relevant until the end of Grade 4. Yet, morphological fluency might start to unfold its relevance for reading and spelling near the end of fourth grade in German.
\end{abstract}

Keywords Morphological awareness · Reading and spelling · German · Primary school children · Phonological processing · Orthographic transparency

Astrid Haase

astrid.haase@uni-goettingen.de

Extended author information available on the last page of the article 
Morphological units (e.g. read +er) are the building blocks of meaning in both oral and written language. Yet, we still know little about how important the handling of such morphological units is in different languages when children learn to read and write. Morphological awareness is a linguistic awareness skill (Apel, 2014) that is defined as the ability to recognize, reflect on and change morphological structures in a language (Carlisle, 1995). It is a subset of morphological processing and involves the conscious awareness of morphemes (Deacon et al., 2008). Morphological awareness gives access to the meaning structure of a language (McBride-Chang, 2004). The ability to recognize morphemes, which refer to the smallest units of meaning in a language (Elsen, 2014), aids children in understanding written language, for example by deducing the meaning of unknown words. Morphological awareness can also aid pronunciation when the reader knows some of the morphemes of a word or recognizes the word as a whole based on its morphemes. With regard to spelling, in many orthographies there is more than one way to spell phonemes or sequences of phonemes (Nunes et al., 1997). Morphological awareness can help choosing the correct spelling based on the meaning structure of the linguistic entity (McCutchen \& Stull, 2015; Nunes et al., 1997).

Morphological awareness has been identified as a meaningful cognitive variable for explaining literacy skills for different languages, for example English (Lee, 2011; Ruan et al., 2018), French (Fejzo, 2016), Greek (Pittas \& Nunes, 2014), Italian (Vernice \& Pagliarini, 2018), Hebrew (Vaknin-Nusbaum et al., 2016), and Chinese (Ruan et al., 2018). Due to differences in the characteristics of languages, evidence for relations between morphological awareness and literacy from studies conducted in a particular language cannot, however, be directly transferred to other languages. For example, German has a rich morphology, especially with regard to inflections and compounds (Elsen, 2014; König \& Gast, 2012). Different facets of morphological awareness (like inflectional, derivational and compound morphology) might play a distinct role when a high number of variants have to be mastered. Like English, German has a high morphological consistency, which means that the spelling of morphemes remains constant in different word forms (Landerl, 2017). However, unlike in English, grapheme-to-phoneme mappings are relatively consistent in German (Schmalz et al., 2015). Still, German is less consistent for spelling than for reading because for spelling the writer has to choose between different phonologically acceptable phoneme-grapheme correspondences, whereas for reading there is mostly only one acceptable pronunciation for a given grapheme (Borgwaldt et al., 2004; Landerl, 2017; e.g. consistency for German monosyllabic words: $47 \%$ in the spelling direction vs. $84 \%$ in the reading direction, see Wimmer \& Mayringer, 2002).

So far, empirical evidence on the relationship between morphological awareness and literacy skills for German is, however, scarce. To the best of our knowledge, to date six studies investigated relations between morphological awareness and literacy skills in German school children (Fink et al., 2012; Görgen et al., 2021; Kargl \& Landerl, 2018; Kargl et al., 2018; Klassert et al., 2018; Volkmer et al., 2019). These studies found relationships between morphological awareness and literacy skills in Grades 2 to 7 . Yet, only two studies with primary school children controlled for other cognitive skills so far (Görgen et al., 2021; Volkmer 
et al., 2019). Thus, more research on the role of morphological awareness for reading and spelling is needed.

\section{The role of orthographic transparency for relations between morphological awareness and literacy skills}

The orthographic transparency of a language (i.e. the number of grapheme-tophoneme and phoneme-to-grapheme mappings) is a moderating factor in the relationship between different cognitive variables and literacy skills (Moll et al., 2014). Morphological awareness might be less relevant for reading and spelling in transparent as compared to opaque orthographies, because when grapheme-to-phoneme and phoneme-to-grapheme mappings are regular, these might be sufficient for reading and spelling (Desrochers et al., 2018). Support for this assumption comes from Desrochers et al. (2018) who investigated second-graders in three languages with descending degrees of orthographic transparency: Greek (most transparent), French and English (least transparent). Morphological awareness uniquely predicted reading comprehension and spelling in all three languages. In English and French, morphological awareness also predicted reading fluency; and only in English, it additionally predicted reading accuracy. This demonstrates that morphological awareness is related to literacy skills across languages but with greater association with literacy skills in less transparent orthographies. Still, even in Finnish, classified as a very transparent orthography (Seymour et al., 2003), morphological awareness is a unique predictor of literacy skills (Müller \& Brady, 2001). German, like Greek, Italian and Spanish, is considered as relatively transparent (Seymour et al., 2003). Yet, in contrast to Italian and Spanish, Greek and German are asymmetric orthographies, that is orthographies more transparent for reading than for spelling, as introduced above (Borgwaldt et al., 2004; Desrochers et al., 2018; Landerl, 2017; Wimmer \& Mayringer, 2002). Thus, investigating the relationship between morphological awareness and literacy in German generates knowledge on how this relationship unfolds in a morphologically rich language with a relatively transparent, but asymmetric orthography.

Based on the finding that orthographic transparency moderates the relationship between morphological awareness and literacy skills, one might expect differential relationships between morphological awareness and reading versus spelling within an asymmetric orthography. For German, this would imply that relations between morphological awareness and literacy skills are stronger for spelling than for reading variables. Yet, so far only one study investigating both spelling and reading skills indicated a stronger relationship of morphological awareness with spelling than with reading (Görgen et al., 2021), while two others did not (Fink et al., 2012; Volkmer et al., 2019). As only three German studies reported relations of morphological awareness with both reading and spelling skills so far, more research is needed on this topic. 


\section{Morphological awareness as a unique predictor of literacy in primary school children}

Across languages, several specific oral language-related factors have been identified to be related with literacy, in particular vocabulary, morphological awareness and phonological processing with its subdomains phonological awareness, rapid naming and phonological working memory (cf. review by Kirby et al., 2008; Moll et al., 2014; Verhoeven \& Perfetti, 2017). Phonological awareness is a person's "sensitivity to, or explicit awareness of, the phonological structure of the words in one's language" (Torgesen et al., 1994, p. 276) and can refer to phonological units of different sizes (e.g., syllable, onset and rime, phoneme; see Goswami \& Bryant, 1990). The development of phonological awareness progresses from an awareness of large phonological units (syllables and rimes) to an awareness of small phonological units (phonemes; see Carroll et al., 2003; Goswami \& Bryant, 1990). Rapid naming describes the ability to retrieve easily and rapidly phonological information from long-term memory (Torgesen et al., 1994) and verbal memory refers to the ability to mentally represent the phonological features of a language (Torgesen et al., 1994). Causal pathways for word reading are clearer with such specific cognitive factors than with broader cognitive factors such as intelligence (Kirby et al., 2008). This is because intelligence is related to a greater variety of different behaviours and skills and therefore its relations to word reading skills are more diffuse than those of specific cognitive factors (Kirby et al., 2008). Thus, it is especially informative to address specific language-related cognitive factors when investigating the unique contribution of morphological awareness to literacy skills. For English, morphological awareness is a unique predictor of literacy skills in school children above and beyond phonological awareness and rapid naming (Desrochers et al., 2018), working memory (Nagy et al., 2006) and vocabulary (Carlisle, 1995).

For German, evidence suggests that phonological awareness skills are more important for spelling, whereas rapid naming is more important for reading fluency (Ennemoser et al., 2012; Landerl \& Wimmer, 2008; Moll et al., 2012). Therefore, both phonological awareness and rapid naming should be accounted for when interested in the unique relationships of morphological awareness with reading and spelling skills in German. Only two studies with school children available to date controlled for such language-related factors. In these studies, morphological awareness uniquely predicted word reading fluency and spelling (Görgen et al., 2021; Volkmer et al., 2019), but not pseudoword reading fluency (Volkmer et al., 2019) in primary school children when controlling for phonological awareness. To the best of our knowledge, German studies that control for other language-related factors and studies that tested the unique contribution of morphological awareness for reading comprehension have not been reported so far.

\section{The role of reading and spelling experience for relations between morphological awareness and literacy}

Another question that has been addressed is whether the relationship between morphological awareness and literacy skills strengthens with literacy competency. While beginning readers mostly rely on logographic and alphabetic/phonological 
reading and spelling strategies, more proficient readers and spellers increasingly use orthographic and morphological strategies by capitalising on orthographic and morphological units (Frith, 1985, 1986; Varnhagen, 1995; but see Wimmer \& Hummer, 1990, concerning the relevance of logographic strategies for beginning readers and spellers in German). Advanced readers and spellers have been shown to apply different strategies for the processing of different words (Donovan \& Marshall, 2016; Goswami, 1988; Sénéchal et al., 2006; Sprenger-Charolles et al., 2003; Varnhagen, 1995). This could imply that morphological awareness increases in its importance with increasing literacy proficiency. Moreover, children's morphological awareness skills increase over the elementary school years (Carlisle \& Fleming, 2003; Kirby et al., 2012; Pittas \& Nunes, 2014). By this, morphological awareness could increasingly aid children's reading and spelling processes. In a meta-analysis covering English and Chinese studies, an increasing relationship was found only between morphological awareness and reading fluency in English but not in Chinese (Ruan et al., 2018). For neither language, there were increases between morphological awareness and reading accuracy or reading comprehension. In addition, in a meta-analysis for the English language by Lee (2011), no systematic increases in the strength of the relationship between morphological awareness and word reading, reading comprehension and spelling in higher grades had been found.

The organisation and development of reading and spelling strategies in German readers and spellers could, however, differ from findings for English or other languages. Due to the rather high consistency of German orthography, German readers and spellers might - at least with respect to reading - rely even with increasing literacy experience strongly on alphabetic strategies. Indeed, alphabetic reading strategies are common in German-speaking first graders (Wimmer \& Hummer, 1990), and even German-speaking second, third and fourth graders seem to rely on grapheme-phoneme-conversions in reading, but do also move to direct word recognition strategies for frequently encountered words (Wimmer \& Goswami, 1994). With regard to spelling, it has been observed that some German children use already after a few months of schooling orthographic elements in their spellings and that after half a year of schooling the majority of children starts to develop orthographic and morphological spelling strategies (Valtin, 1997). Thus, in German, relations between morphological awareness and reading might strengthen more slowly and to a lesser extent than relations between morphological awareness and spelling.

To the best of our knowledge, existing cross-sectional studies comparing German children from different age groups /grades with respect to relations between morphological awareness and literacy skills have with one exception (Görgen et al., 2021), however, exclusively focused on spelling, and have neglected reading. Klassert et al. (2018) found that morphological awareness was related to spelling skills in third-graders, but not in first- and second-graders. The authors argue that younger school children, although already having well-developed morphological awareness skills, cannot reliably use them for spelling decisions, yet (Klassert et al., 2018). In a recent study by Görgen et al. (2021), the absolute strength of relations between morphological awareness and spelling did not seem 
to change from Grade 3 to Grade 4, but when other predictors were taken into account the unique contribution of morphological awareness for spelling was higher in Grade 4 than in Grade 3. A study with children from Grades 4 to 7 showed strong relations between morphological awareness and spelling, but no systematic increase in the strength of these relations with increasing grade level (Kargl et al., 2018). In a similar vein, Kargl and Landerl (2018) found no differences in the relationships between morphological awareness and spelling skills between Grades 4 till 7. Thus, while in German the relations between morphological awareness and spelling might strengthen with increasing grade level between Grades 1 and 4 (Görgen et al., 2021; Klassert et al., 2018), there seems to be no such increase between Grades 4 and 7 (Kargl \& Landerl, 2018; Kargl et al., 2018). These diverging results concerning a change of relevance over school years might indicate that the strengthening of relations does already occur in early primary school grades. The differing results might, however, also stem from methodological differences, such as differences in the task type used to assess morphological awareness (lower grades: judgement tasks; higher grades: production tasks), differences in the task format (lower grades: oral or partly oral task format; higher grades: written task format) or differences in the response format employed (lower grades: choice from response alternatives; higher grades: written response format). Therefore, more research on relations between morphological awareness and literacy skills in German children from different grade levels is needed.

\section{The present study}

From the theoretical considerations and empirical findings introduced above, we deduced three research questions on relations between morphological awareness and literacy skills in German school children of different age groups.

\section{How is morphological awareness related to different literacy competencies in the asymmetric orthography of German?}

International studies with school children imply a stronger relationship between morphological awareness and literacy skills in opaque orthographies than in transparent ones. German is a language with a rather transparent orthography, but with higher orthographic consistency for reading than for spelling. Thus, German is an interesting test case as to whether morphological awareness is more relevant for spelling than for reading in a language with a rather transparent, but asymmetric orthography. Outcomes of previous German studies on this question were equivocal. The current study investigated relations of morphological awareness with a wider range of literacy skills than previously explored including different reading (fluency, comprehension) and spelling (correctly written graphemes, spelling strategies) skills. 
2. Does morphological awareness uniquely predict literacy skills above and beyond other language-related cognitive skills in German?

Besides morphological awareness, other language-related skills such as phonological processing skills and vocabulary are associated with literacy competencies. For German, two previous studies tested the unique contribution of morphological awareness on literacy skills when accounting for phonological awareness (Görgen et al., 2021; Volkmer et al., 2019). Their results suggest a unique contribution of morphological awareness to reading fluency and spelling in second and third to fourth grade, respectively. No previous German study controlled for further cognitive variables related to oral language, so far. To expand our knowledge about the specific association of morphological awareness with literacy competencies in German, the current study controlled for phonological awareness, rapid naming, phonological working memory and vocabulary and additionally addressed reading comprehension.

3. Is the relationship between morphological awareness and literacy skills stronger in children who are more literacy-proficient?

At present, empirical evidence is inconclusive as to whether relations between morphological awareness and literacy skills strengthen with increasing grade level, that is with increasing reading and spelling experience. Previous German studies on this topic focused on spelling, while there is little research on potential grade-level differences in the relationship between morphological awareness and reading. The current study used a cross-sectional design to investigate German second-, third-, and fourth-graders with comparable tasks between grade levels covering different reading and spelling skills.

\section{Methods}

\section{Sample}

Participants were second-, third- and fourth-graders speaking German as a first language from nine primary schools in Thuringia, Germany. Children's socioeconomic status was roughly comparable between grades: We measured three socio-economic variables with a parental questionnaire: 1. Number of books at home, a question adapted from PISA 2000 (Haider \& Böck, 2001) that is internationally used for measuring socio-economic status (e.g. Gustafsson et al., 2018), 2. Highest school leaving certificate of responding parent and 3. Highest professional education of responding parent. Using Kruskal-Wallis tests, we observed that socio-economic variables did not differ significantly between grades, with one exception: parents of second graders obtained on average higher school leaving certificates than parents of fourth graders did $(p<.05)$. All children were tested at the end of the school year. Altogether, $n=135$ second graders, $n=109$ third graders and $n=107$ fourth graders took part in data collection. Fifty-five 
percent of students within this sample were female. Children's data were excluded from all analyses when they did not speak German as a first language (defined as growing up with German as a major language since birth and speaking German at home at least half of the time, based on responses from the parent questionnaire complemented by information given by the children themselves during testing; $n=31$ ). Concerning the main research questions, children were additionally excluded if they were not able to participate in all three test sessions $(n=6)$, when there were disruptions at any of the test sessions $(n=11)$ and when any of the diagnostic test results were not interpretable (as children were familiar with parts of the test material or norm data were not available for children's age; $n=12$ ). The final sample sizes for analyses concerning the main research questions were $n=119$ second graders, $n=87$ third graders and $n=85$ fourth graders. Some children were older than the typical age range of the respective grade, indicating that they had either spent an extra kindergarten year or that they had repeated a school year (Grade 2: 8 out of 119 children, 6.7\%; Grade 3: 8 out of 87 children, $9.2 \%$; Grade 4: 9 out of 85 children, $10.6 \%$ ).

With respect to analyses of the factorial structure of the morphological awareness tasks reported below, data sets from $n=126$ second graders, $n=94$ third graders and $n=90$ fourth graders were used $(n=31$ of the participating children did not speak German as a native language, $n=6$ children missed the test session in which the morphological awareness tasks were conducted, in $n=3$ of the respective test sessions distortions occurred, and $n=1$ child advanced from first to second grade only in the week of testing).

This study was conducted in accordance with applicable Thuringian laws on schooling and data protection (Thüringer Schulgesetz, Thüringer Datenschutzgesetz) and followed the recommendations of the Thuringian Ministry of Education, Youth, and Sports. It was approved by the educational authority for the region of central Thuringia (Staatliches Schulamt Mittelthüringen). The assessment of this study comprised reviews on ethical standards and data privacy requirements for conducting studies with school children in schools and during lessons. Additional approval by an ethics committee was not required in compliance with institutional and federal (Thuringian) guidelines and regulations. Written informed consent was obtained from parents of participating children.

\section{Diagnostic instruments to assess reading, spelling and language-related control variables}

To assess reading and spelling skills and language-related cognitive control variables (phonological awareness, verbal memory, rapid naming, and vocabulary), standardized diagnostic tests normed for the respective age groups were used. With one single exception (see "vocabulary"), testing procedure followed exactly the guidelines for the respective tests. 


\section{Reading fluency}

Real word reading fluency (direct word recognition) and pseudoword reading fluency (synthetic reading based on grapheme-phoneme correspondence rules) were measured with the SLRT-II (Weiterentwicklung des Salzburger Lese- und Rechtschreibtests SLRT, Moll \& Landerl, 2014). For each subtest, children are presented with a card containing 156 words or pseudowords, respectively. For each of the two cards, the child is given one minute to read aloud the printed words as fast and as accurately as possible. All reading sessions were audio recorded. Based on the recordings, the numbers of correctly read words and pseudowords were identified. The respective subtests of the SLRT-II can be applied over a wide age range. For primary school children, they are normed with respect to grade level. The manual reports parallel form reliabilities of $.93 \leq r \leq .98$ for word reading and $.90 \leq r \leq .96$ for pseudoword reading for second to sixth grade. Raw scores for the number of correctly read (pseudo-)words within the given testing time of one minute were used in analyses.

\section{Reading comprehension}

Reading comprehension was measured with the paper-and-pencil-version of the ELFE II (Ein Leseverständnistest für Erst- bis Siebtklässler - Version II, Lenhard et al., 2017). In this speed test, reading comprehension is measured via silent reading of words, sentences and text passages in children from Grade 1 to 7 . According to the manual, overall split-half reliability across all subscales for the paper-pencil version is $r_{\mathrm{tt}}=.96$. Per grade, a mean $T$-value across all three subscales was used in analyses. Testing time for the subscale word-reading comprehension was not measured accurately in one group session because of a technical failure with the stopwatch. Therefore, the mean reading comprehension $T$-value was computed from the scores for sentence- and text-reading comprehension for ten fourth graders. Likewise, means of the two correctly executed subscales were used for five further participants, who did not correctly follow the instructions for one of the subscales.

\section{Spelling}

Spelling was measured using the HSP (Hamburger Schreibprobe, May, 2013). This test measures spelling abilities via the writing of single words and sentences. In line with the HSP manual, test books HSP 2, HSP 3 and HSP 4-5 were used for the respective grade levels. The test can be analysed with respect to the number of correctly written words and graphemes as well as the usage of three spelling strategies (alphabetic strategy, orthographic strategy, morphological strategy). The analysis of spelling strategies is performed by focusing on the spelling of specific parts of words that is indicative of the use of the respective strategy. An alphabetic spelling strategy makes use of phoneme-grapheme-conversions, as for example $/ \mathrm{f} /-<\mathrm{f}\rangle$, $/ \mathrm{r} /-<\mathrm{r}>$ in the German word fragt [Eng. asks]. An orthographic spelling strategy relies on the application of orthographic rules. As an example, in German, short vowels are orthographically marked by double consonants following the short vowel 
as in the German word Koffer [Eng. suitcase]. The spelling $<\mathrm{ff}>$ cannot be deduced by a simple reliance on grapheme-phoneme conversions, as the double consonant is pronounced as a single phoneme (in this case /f/). A morphological spelling strategy requires reference to the morphological structure of words. For example, the writing of the German word Fahrrad [Eng. bike] with $<\mathrm{rr}>$ (pronounced as single $/ \mathrm{r} /$ ) can only be inferred by decomposing it into its two constituting morphemes (Fahr - rad) [literally drive-wheel]. Students received one point for each correctly spelled grapheme, and, regarding spelling strategies, for correctly spelled word parts representing the respective spelling strategies. Responses were rated using an automated database comparison within an online tool provided by the HSP. The manual of the HSP reports for all three grades an internal consistency of $r=.98$ for correctly written graphemes. Internal consistency is $.82 \leq r \leq .87$ for the alphabetic spelling strategy, $.91 \leq r \leq .92$ for the orthographic spelling strategy and $.86 \leq r \leq .87$ for the morphological spelling strategy. In analyses, raw scores for correctly written graphemes and for alphabetic, orthographic and morphological spelling strategies were used.

\section{Phonological awareness}

The phonological awareness subtest of the P-ITPA (Potsdam-Illinois Test für Psycholinguistische Fähigkeiten, Esser \& Wyschkon, 2010) as applied with school children was used. This test is normed until age 11;5 (years;months) and consists of a vowel exchange task (replacing one or more vowels in the target words; 22 items, maximum score: 22 points) and a consonant deletion task (omitting one or more consonants in the target words; 22 items, maximum score 22 points). A third task, the rhyme task, is only used with school children if they do not reach the threshold criterion in the vowel exchange task. Otherwise, children are automatically credited with full points for the rhyme task (20 items, maximum score: 20 points). According to the procedure for analysing the test results, the scores per task are summed up to form a phonological awareness score (maximum score 64 points; see Esser \& Wyschkon, 2010). High correlations between the vowel exchange and the consonant deletion task in our sample indicate the feasibility of this approach (correlations for Grades 2, 3 and 4: .64, .64 and .59, all $p<.001$ ). In the vowel exchange and consonant deletion task, children have to apply changes to real words that result either in another real word (vowel exchange: 12 items; consonant deletion: 16 items) or in a pseudoword (vowel exchange: 10 items; consonant deletion: 6 items). Word length in the vowel exchange task ranges from one to four syllables, while the word length in the consonant deletion task ranges from one to three syllables. The authors of the P-ITPA report that the vowel exchange task is more difficult than the consonant deletion task (Esser \& Wyschkon, 2010). This was confirmed in our sample (mean sum score vowel exchange for Grades 2, 3 and 4: 12.29, 14.67 and 15.68 points; mean sum score consonant deletion for Grades 2, 3 und 4: 16.14, 17.49 and 18.21 points).

The manual reports Cronbach's $\alpha$ values of $\alpha=.96$ for the rhyme task, $\alpha=.94$ for the vowel-change task and $\alpha=.95$ for the consonant elision task. The reliabilities we observed in our sample were lower, but still adequate to good, meaning that we tested phonological awareness reliably (Grade 2: vowel exchange $\alpha=.87$, consonant 
deletion $\alpha=.82$; Grade 3: vowel exchange $\alpha=.83$, consonant deletion $\alpha=.78$; Grade 4: vowel exchange $\alpha=.86$, consonant deletion $\alpha=.85$ ). Raw scores were used in statistical analyses.

\section{Verbal memory}

Verbal memory was measured with the pseudoword repetition subtest of the ZLTII (Züricher Lesetest-II, Petermann \& Daseking, 2015), which is applicable until Grade 8 . Children have to repeat 25 pseudowords increasing in complexity, that is increasing in the number of syllables they contain (from two to six). The manual reports re-test reliability across all grade levels as $r=.79$. The raw score of the number of mistakes was used in analyses.

\section{Rapid naming}

Version 1 of the rapid naming subtest of the ZLT-II (Petermann \& Daseking, 2015) was used. Five pictures of highly familiar objects (such as car or sun) are printed repeatedly in pseudo-random order on a card. Children have to name the pictures as quickly and as correctly as possible. The manual reports a re-test reliability across all grade levels of $r=.94$. The time needed to name all 30 pictures was measured and used in analyses.

\section{Vocabulary}

An adaption of the vocabulary subtest of the $K E K S$-test battery (Kompetenzerfassung in Kindergarten und Schule, May \& Bennöhr, 2013) was used. In this vocabulary group test, children are asked to select the one of four words that semantically fits best into a given sentence. In line with the manual's recommendations, test book KEKS Deutsch $3 A$ was used for second graders, test book KEKS Deutsch $4 A$ for third graders and KEKS Deutsch $4 \ddot{U}$ for fourth graders. An adaption was implemented to minimise potential disadvantages for children with lower reading skills: Instead of letting children read the test items on their own, the conductor of the test read all items aloud and asked participants to read with her. By this, reading is not necessary to respond to the items. The manual reports Cronbach's $\alpha$ values for the unadapted vocabulary subtests of $.77 \leq \alpha \leq .82$ for the respective grades. We observed lower values of Cronbach's $\alpha$ for our adapted measure: .53 $\leq \alpha \leq .64$. Raw scores were used in further analyses.

\section{Morphological awareness tasks}

As there is no standardized and normed diagnostic test of morphological awareness available in German for children from Grades 2 to 4, and we intended to measure morphological awareness with oral production tasks covering various facets of morphological awareness (inflection, derivation, compounding, morphological fluency), we compiled and adapted existing German morphological awareness tasks from 
different sources (for details, see below) for use in the current study. These are, however, partly intended for somewhat younger or older age groups. Additionally, some of them originally make use of a written presentation and response format. Thus, the compiled tasks were extensively piloted in two studies aiming at testing the applicability of an oral presentation and response format (pilot study 1 with $N=61$ adults), at excluding items that appear to produce bottom or ceiling effects in the intended age groups, and at ensuring that the chosen implementation format is appropriate for second- to fourth-graders (pilot study 2 with $n=20$ second graders and $n=11$ fourth graders). As a result of piloting, the tasks and items described below were used in the current study.

\section{Pseudoword Cloze Task}

Internationally, pseudoword cloze tasks have been widely used to measure morphological awareness in children (e.g. Berko, 1958; Casalis \& Louis-Alexandre, 2000; McBride-Chang et al., 2005; Robertson \& Deacon, 2019; Robertson et al., 2013). Our pseudoword cloze task measures the ability to produce German inflections, derivations and compounds in a pseudoword context. The pseudowords to be changed morphologically are embedded into a grammatically correct real-word-sentence context. The task contains 14 items on inflections, 17 items on derivations and 8 items on compounds. Items were taken and adapted from the pseudoword subtest of the $T M B$ (Test zur Erfassung der morphematischen Bewusstheit, see Fink et al., 2012), and the plural-singular subtest, the adjective derivation subtest and the morpheme derivation subtest of the HSET (Heidelberger Sprachentwicklungstest, Grimm \& Schöler, 1991) and supplemented by compound items provided by Hasenäcker and Schroeder (2017). Pseudowords consisted of pseudo stems and-if morphologically necessary - a legal grammatical marking of German. In the following examples, the pseudoword stem is given in bold and affixes are separated from the stem via hyphens. Items on inflections comprised changes from singular to plural and from plural to singular in nouns, from positive to comparative and superlative in adjectives and from infinitive to past participle in verbs (e.g. ,Sie kann jederzeit an$\boldsymbol{k u b}$-en. Vorgestern hat sie uns ...." / Eng. "She can ankub anytime. The day before yesterday she has ... us."; Answer: "an-ge-kub-t" / Eng. "ankubed”). Items on derivations comprised word formations of nouns and verbs into male persons, female persons, location nouns, diminutives and adjectives (e.g. "Peter grell-t schnell. Er ist ein schneller...". Eng. Peter grells quickly. He is a quick..."; Answer: "Greller" / Eng. "greller"). Items on compounds comprised compositions and decompositions of non-existing compounds (e.g. "Eine Decke zum Mank-en ist eine ...." Eng. "A blanket for manking is a...."; Answer: "Mankdecke" / Eng. "manking blanket"). Items stemming from the HSET included pictures that were also used in the current study. As items stemming from the TMB and from Hasenäcker and Schroeder (2017) came without pictures, the adapted items used in the current study were presented without pictures.

We adapted the original material with regard to the presentation of items and the rating of responses. For all items, an oral presentation and response format was used to rule out influences of reading and spelling skills. Furthermore, recordings of a 
trained speaker were used for the presentation of all items to increase objectivity of implementation. To verify that participants heard the pseudowords correctly, they had to repeat the pseudoword before applying the morphological change. If students failed twice to repeat the pseudoword correctly, we rated the morphological change in their response depending on how they had pronounced the pseudoword.

To assure consistency of ratings across the items from the HSET, the TMB and from Hasenäcker and Schroeder (2017), a category system was set up. Rules aligned with the rating guidelines of the HSET, the TMB and the compound task, and were fine-tuned based on different grammatical resources (Dudenredaktion, 2016; Fleischer \& Barz, 2012; Gallmann, 2016; Kotulková, 2004). Two points were given for completely correct answers, one point for partly correct answers and zero points for false or no answers. The decision to give credit to partly correct answers follows the suggestions and scoring system of the HSET: The authors (Grimm \& Schöler, 1991) of the HSET explicate that partly correct responses show that the child understood the semantic relations in the item and formed an answer based on a grammatical rule, a response however not perfectly concordant with the actual rule that had to be applied. For instance, a child using the suffix "-lig" instead of the correct "-ig" to mark an adjective applied a suffix very similar to the correct one. In such a case, a dichotomous false/correct rating would underestimate the child's ability (Grimm \& Schöler, 1991). The category system reached good to very good inter-rater reliability with Spearman's rho between $.81 \leq \rho \leq 1.00$. Across second to fourth grade, Cronbach's $\alpha$ for the pseudoword cloze task was $\alpha=.82$.

\section{Morphological Fluency Task}

Morphological fluency tasks are particularly useful for measuring the ability to produce complex words using morphological knowledge (Casalis et al., 2004). Internationally, these tasks have drawn little attention up to this point, but a number of studies have already successfully applied them with children (Casalis et al., 2004; Quémart \& Casalis, 2017). Our morphological fluency task uses items from the morphological fluency subtest of the TMB transferred into an oral presentation and response format. Children had to name as many different words as they could find that came from the same word family as the test word. Correct responses could be derivations or compounds. For instance, for the test word "fahren" (Eng. "[to] drive"), children could produce "Fahrer", "Fahrweg", "wegfahren" (Eng. "driver", "driveway", "to drive off") and so on. From the results of the two pilot studies mentioned above, a suitable testing time for primary school children was inferred and set to $30 \mathrm{~s}$ per item. The TMB uses four items to test morphological fluency in both version 1 and version 2 . We kept the number of items, but as the TMB was originally used with an older age group, we selected the test items of versions 1 and 2 that children should be most familiar with. For this purpose, all original test items were collated with the German Children's Book Corpus (ChildLex) that contains over ten million words from 500 books written for children between 6 and 12 years (Schroeder et al., 2015). The four items with the highest type frequencies of the morphological family size, an indicator specifying in how many different words in the ChildLex corpus the stem of the word is used, were chosen as test items because 
participants should be familiar with a number of derivations and compounds of these items. Being familiar with more derivations and compounds should make the morphological fluency task easier and by this appropriate for our younger participants.

Rating criteria for responses were adapted in line with the ones of the pseudoword cloze task, that is differentiating between fully correct, partly correct and false responses. Fully correct responses were word formations that were etymologically related to the test word and were in usage in the German language. The latter was checked using two corpora: Deutsches Nachrichten-Korpus (Abteilung Automatische Sprachverarbeitung, 2011) and the DWDS (Berlin-Brandenburgische Akademie der Wissenschaften, n.d.). This criterion was chosen, because some children formed highly unusual words, such as "Flugzeugfahren" (Eng. "driving a plane") which is usually not expressed as a compound in German. To acknowledge that such a word could principally be formed this way according to the morphological rules of the German language, 1 point was awarded. Zero points were given for inflections ("Ich fahre", Eng. "I drive"), etymologically unrelated words ("Gefahr", Eng. "danger") and simple repetitions of the test word. The category system reached good to very good inter-rater reliability for all four test words with Spearman's rho between $.83 \leq \rho \leq .92$. Cronbach's $\alpha$ of the morphological fluency task was $\alpha=.76$ across Grades 2 to 4 .

\section{Procedure}

All test sessions took place between April and June 2018 in children's schools. The tasks were administered in two group sessions and one individual session, which all lasted approximately $45 \mathrm{~min}$. The first two sessions were group sessions: In the first session, children's spelling abilities and vocabulary knowledge were tested. In the second session, reading comprehension was assessed. Group sessions were administered in a classroom. For the third session, the individual session, a quiet room on the school grounds was used. First, morphological awareness was tested with the morphological fluency task followed by the pseudoword cloze task. After that, the child's verbal memory, rapid naming ability, phonological awareness and reading fluency were assessed. Each group session was implemented by two test conductors (the first author or a trained student assistant assisted by a further student assistant) and each individual session was conducted by one test conductor (the first author or one of four trained student assistants).

\section{Statistical analyses}

Before investigating the research questions, the items reliably representing the construct morphological awareness were identified using factor analyses. Then, our research questions were answered with correlation analyses and multiple linear regressions. 


\section{Results}

Factor analyses were run in MPlus (Muthén \& Muthén, 2018). The pseudoword cloze task comprises items on inflections, derivations and compounds. As a validity check, we assessed whether this structure was represented in the data using factor analyses. In exploratory factor analysis, the interpretability of different factor solutions was inspected (oblique GEOMIN rotation, Estimator: WLSMV). An 8-factor solution provided meaningful factors and had adequate to good descriptive model fit indices $\left(\mathrm{RMSEA}=.03, p_{\mathrm{RMSEA}}>.99 ; \mathrm{CFI}=.96 ; \mathrm{TLI}=.94 ; \chi^{2}=593.88\right.$, $d f=457, p<.01)$ as indicated by an RMSEA $\leq .05$ with a probability of $p_{\text {RMSEA }}>.95$ for indeed being below .05, a CFI $\geq .95$, and a TLI $\geq .90$ (Kleinke et al., 2017). The $\chi^{2}$-test of model fit was significant indicating some misfit, but as $\chi^{2}$ is sensitive to sample size, it is not recommended to use this test as the sole base for acceptance or rejection of a model (Kleinke et al., 2017; Schreiber et al., 2006). As the RMSEA, the CFI and the TLI are less sensitive to sample size (Kleinke et al., 2017; Schreiber et al., 2006), the plausibility of the model was accepted. The eight factors reflect different types of inflections (plural on -e, plural on $-s$ ), derivations (agent noun, location noun, diminutive), compounds (compound) and task-based similarities between items regarding word class or presentation mode and tapping both inflections and derivations (adjective, TMB). The factor adjective includes noun-to-adjective derivations, and comparative and superlative inflections. The factor $T M B$ comprises all items from the TMB (seven derivations of various kinds and one inflection). Plural-to-singular noun inflections could not be assigned to a factor and were therefore omitted from further analyses.

Using confirmatory factor analyses, we tested whether the morphological fluency task and the pseudoword cloze task measure two different facets of morphological awareness or could be grouped on one factor (estimator: WLSMV). Our one-facet model assumed morphological awareness was predicted by all pseudoword cloze task and morphological fluency items directly. Our two-facet model assumed morphological fluency to be a first-order factor predicted by the four morphological fluency items, pseudoword cloze task to be a second-order factor predicted by the factors found in exploratory factor analysis and morphological awareness to be a third-order factor predicted by morphological fluency and pseudoword cloze task. To successfully run the two-facet model, we had to omit the first-order factor location noun because of a negative residual variance leaving seven factors to predict pseudoword cloze task. Results demonstrated the superiority of the two-facet model (RMSEA $=.03, p_{\mathrm{RMSEA}}>.99 ; \mathrm{CFI}=.95$; $\left.\mathrm{TLI}=.94 ; \chi^{2}=758.94, d f=621, p<.01\right)$ compared to the one-facet model as indicated by higher RMSEA and lower CFI and TLI values in the one-facet model $\left(\mathrm{RMSEA}=.08, p_{\mathrm{RMSEA}}<.01 ; \mathrm{CFI}=.63 ; \mathrm{TLI}=.61 ; \chi^{2}=2060.06, d f=702\right.$, $p<.01)$. Although the two-facet model had a significant $\chi^{2}$-test, we accepted the plausibility of this model because of $\chi^{2}$ 's dependency on sample size and because all other model fit indices were adequate or good.

Results indicate that the pseudoword cloze task and the morphological fluency task measure two aspects of the underlying construct morphological awareness. 
Therefore, morphological awareness was represented with these two variables in subsequent analyses. To create the variables used in further analyses, sum scores were calculated for both the pseudoword cloze task and the morphological fluency task, adding up all correct responses to the items included in the two-facet model. That is, of the originally 39 pseudoword cloze task items, the four inflectional items on forming a singular and the two derivational items on describing a location were omitted leaving 33 items for this task with a maximum score of 67 points (for 32 items a maximum of two points could be gained and for one item a maximum of three points could be gained because of an additionally required vowel shift; see Methods section). Reliability indices for the reduced set of items were $\alpha=.79$ in second grade and $\alpha=.81$ in third and fourth grade, respectively. The sum score for morphological fluency consisted of all correct and partly-correct responses produced for the four items (see Methods section). In this task, there was no predetermined maximum score as participants could produce as many word formations as they could find in the given time.

Descriptives of our study variables are presented in Table 1.

Correlations were computed for each grade separately. Table 2 displays the correlations of language-related cognitive variables and age with literacy variables. The ability to apply morphological changes to pseudowords correlated significantly with all literacy variables in all grades. Morphological fluency correlated significantly with correctly spelled graphemes, orthographic spelling strategy and reading comprehension in all three grades, but with morphological spelling strategy, word reading fluency and pseudoword reading fluency only in fourth grade and with alphabetic spelling strategy only in second grade. Of the other cognitive variables, phonological awareness stood out with high correlations with literacy variables across all grades. Age correlated negatively with several literacy variables in third and fourth grade, indicating that younger school children within third and fourth grade tended to outperform their older peers. Table 3 displays intercorrelations between the language-related cognitive variables and age. Both morphological awareness variables were related to phonological awareness, verbal memory and vocabulary in all three grades.

When checking assumptions for regressions, we found that the assumption of uncorrelated errors was violated for the alphabetic spelling strategy as indicated by scatterplots of the standardised values that are predicted by the model and the standardised errors, that is the standardised differences between the observed and the predicted values of the outcome variable (cf. Field, 2018). As such, only regression coefficients but not significance tests are interpretable for the alphabetic spelling strategy (cf. Field, 2018). For the other regression analyses, significance tests were considered valid.

Multiple linear regression analyses are displayed in Table 4 for spelling variables and in Table 5 for reading variables. Phonological awareness was the strongest predictor for all outcome variables in all grades. Further, rapid naming significantly contributed to explaining variance in the orthographic spelling strategy in second and third grade, and in pseudoword reading fluency in second grade. Age significantly explained variance in the morphological spelling strategy in third grade. Its negative regression coefficient indicates that older students tended to reach lower 


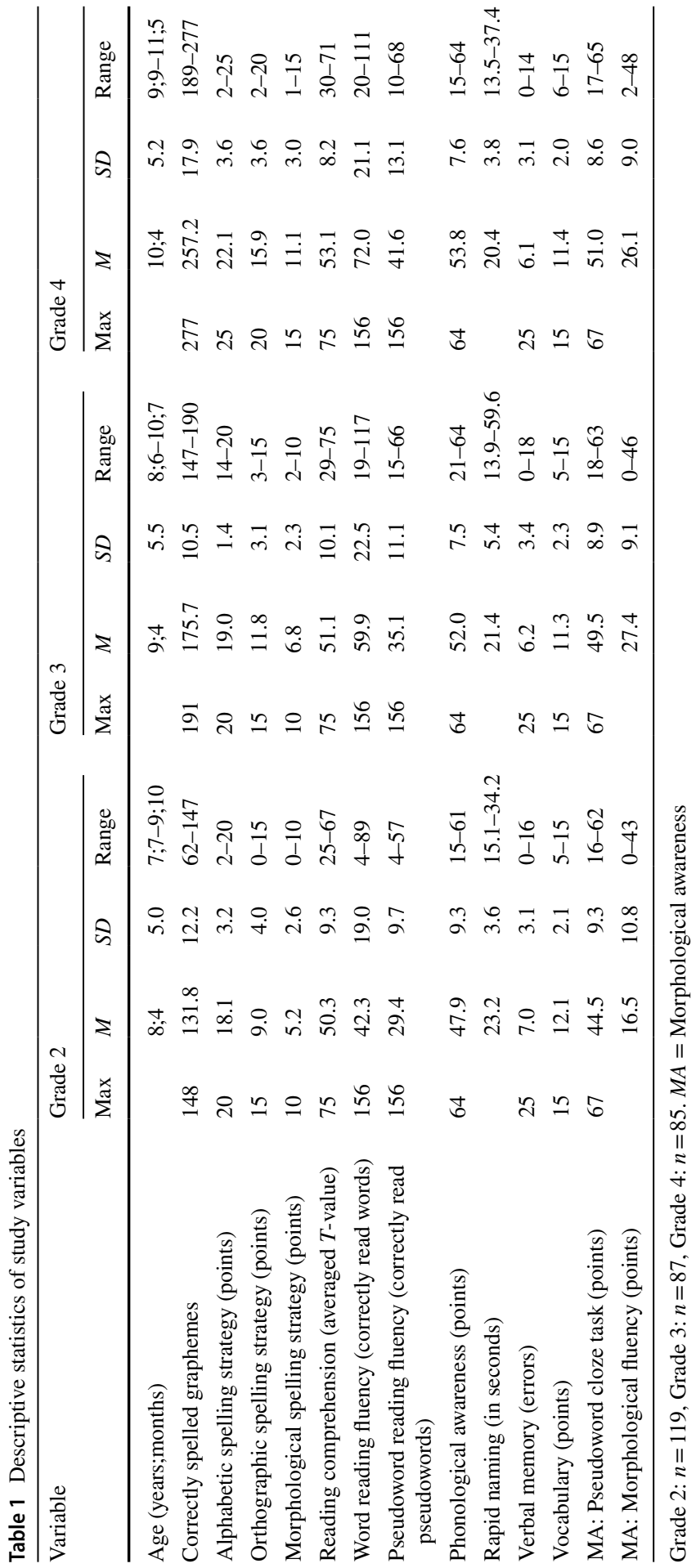




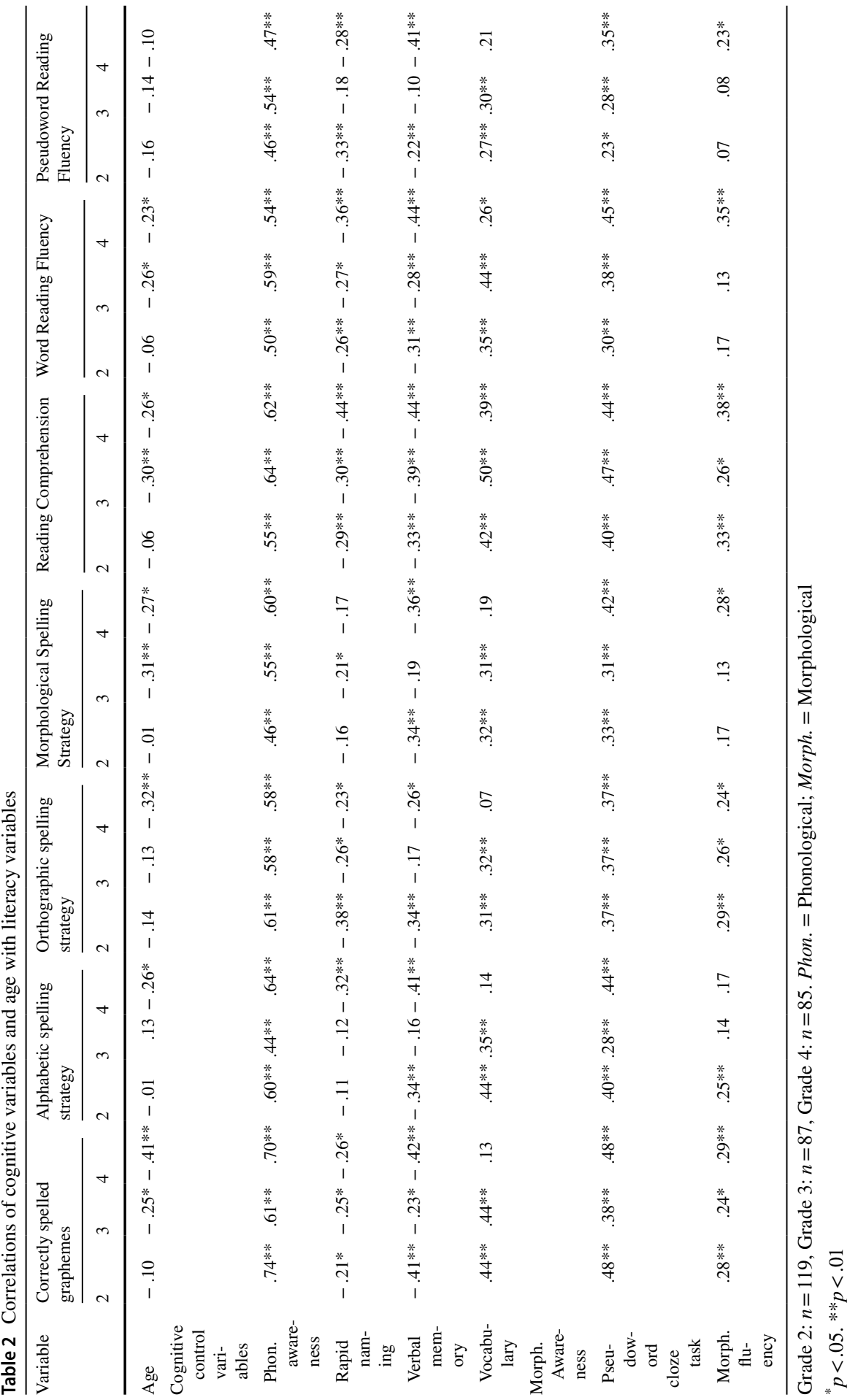




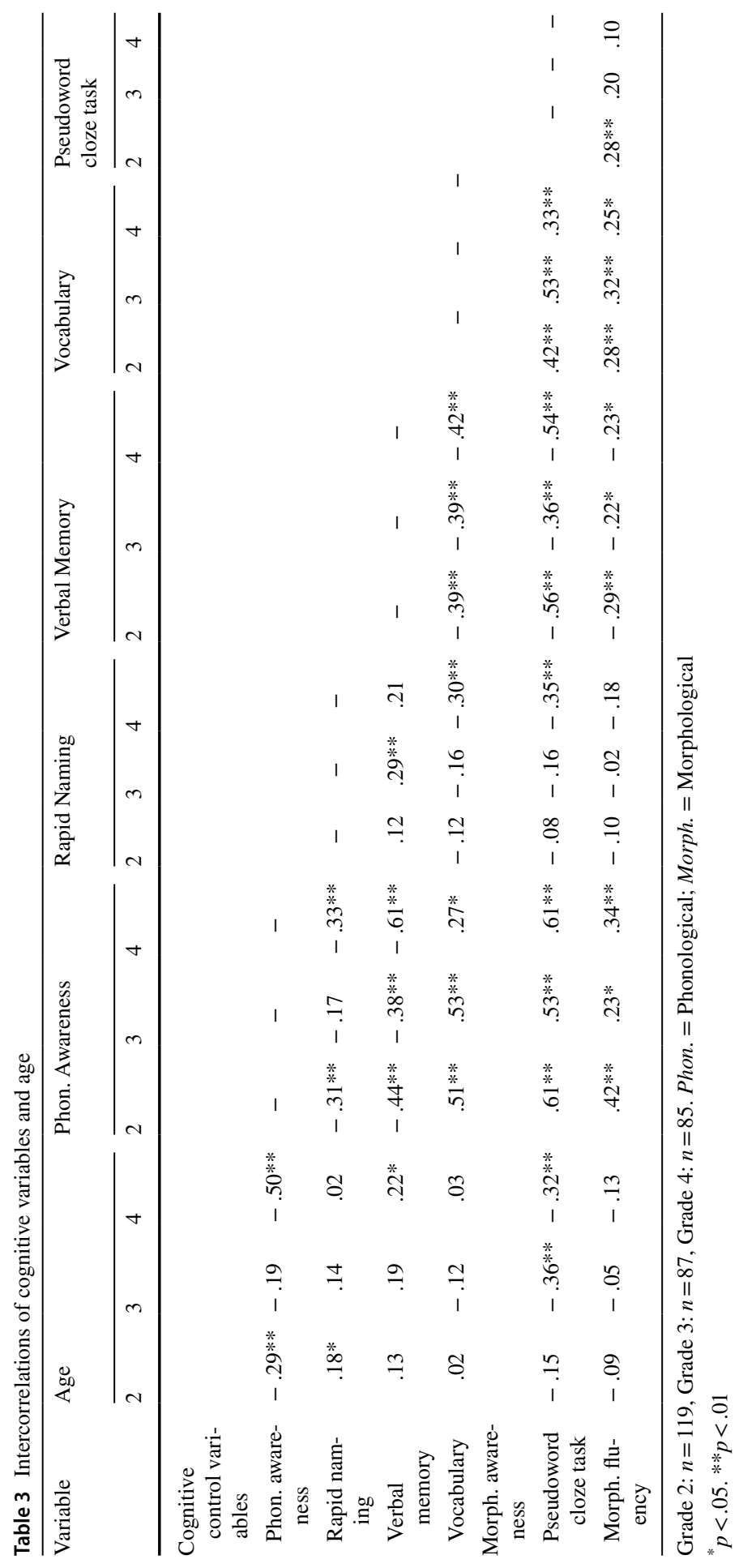




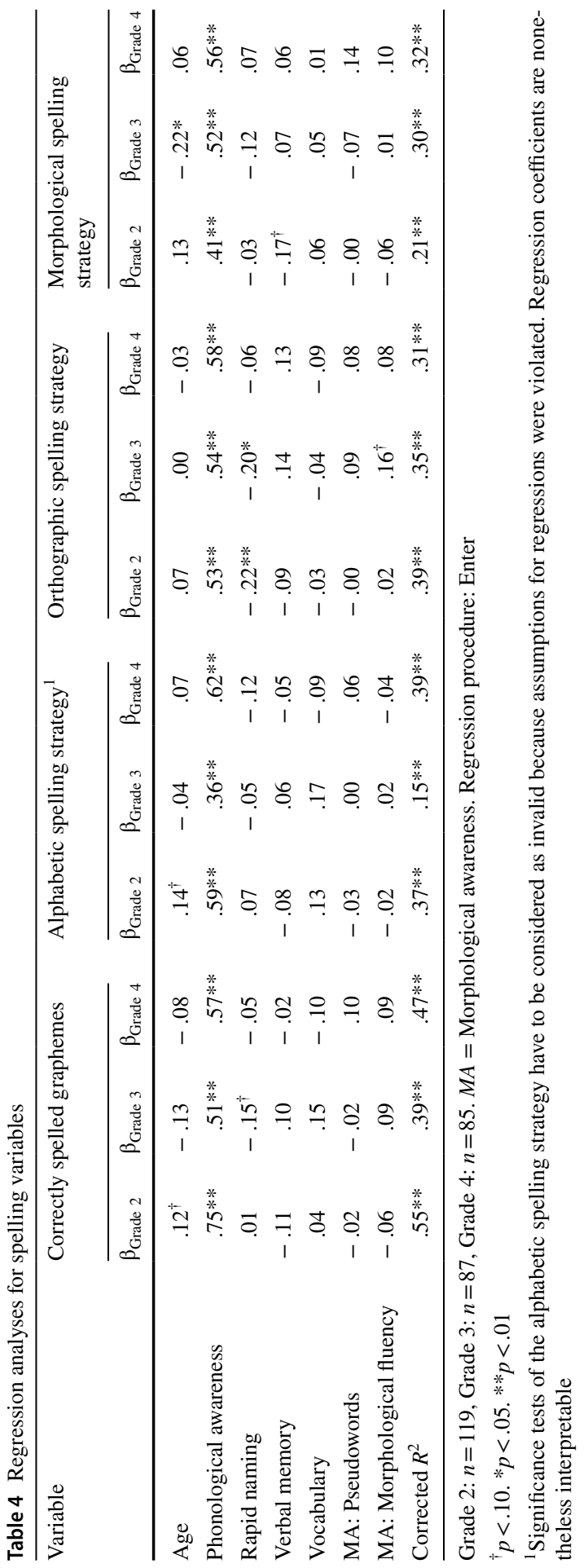


Table 5 Regression analyses for reading variables

\begin{tabular}{|c|c|c|c|c|c|c|c|c|c|}
\hline \multirow[t]{2}{*}{ Variable } & \multicolumn{3}{|c|}{ Reading comprehension } & \multicolumn{3}{|c|}{ Word reading fluency } & \multicolumn{3}{|c|}{$\begin{array}{l}\text { Pseudoword reading } \\
\text { fluency }\end{array}$} \\
\hline & $\beta_{\text {Grade } 2}$ & $\beta_{\text {Grade } 3}$ & $\beta_{\text {Grade } 4}$ & $\beta_{\text {Grade } 2}$ & $\beta_{\text {Grade } 3}$ & $\beta_{\text {Grade } 4}$ & $\beta_{\text {Grade 2 }}$ & $\beta_{\text {Grade } 3}$ & $\beta_{\text {Grade } 4}$ \\
\hline Age & .09 & $-.15^{\dagger}$ & -.01 & .10 & -.14 & -.00 & -.01 & -.05 & .14 \\
\hline Phonological awareness & $.35^{* *}$ & $.45^{* *}$ & $.44 * *$ & $.44 * *$ & $.47 * *$ & $.25^{\dagger}$ & $.45^{* *}$ & $.56^{* *}$ & $.34^{*}$ \\
\hline Rapid naming & $-.16^{\dagger}$ & $-.15^{\dagger}$ & -.12 & -.13 & $-.15^{\dagger}$ & $-.18^{\dagger}$ & $-.20^{*}$ & -.12 & -.11 \\
\hline Verbal memory & -.04 & -.06 & -.01 & -.13 & -.03 & -.12 & -.05 & .17 & -.18 \\
\hline Vocabulary & .15 & .17 & $.18^{\dagger}$ & .10 & $.19^{\dagger}$ & -.01 & .07 & .07 & -.03 \\
\hline MA: Pseudowords & .08 & .03 & .04 & -.05 & -.03 & .16 & -.07 & -.03 & .05 \\
\hline $\begin{array}{l}\text { MA: Morphological } \\
\text { fluency }\end{array}$ & .11 & .07 & $.16^{\dagger}$ & -.07 & -.03 & $.19^{\dagger}$ & -.15 & -.03 & .08 \\
\hline Corrected $R^{2}$ & $.33 * *$ & $.47 * *$ & $.42 * *$ & $.25^{* *}$ & $.36^{* *}$ & $.33 * *$ & $.23 * *$ & $.26^{* *}$ & $.22 * *$ \\
\hline
\end{tabular}

Grade 2: $n=119$, Grade 3: $n=87$, Grade 4: $n=85$. $M A=$ Morphological awareness. Regression procedure: Enter

${ }^{\dagger} \mathrm{p}<.10 . * \mathrm{p}<.05 . * * \mathrm{p}<.01$

values for morphological spelling than younger students did. The adjusted $R^{2}$ s were significant in all instances. Morphological awareness variables did not explain additional variance.

In the regression analysis on word reading fluency in fourth grade, 33\% of variance was explained, although none of the predictors surpassed the significance level of $p<.05$. This can happen when there are several predictors in a model that are similarly predictive of the outcome variable because each regression coefficient represents the predictive power of its variable when all other variables are held constant (Field, 2018). Therefore, if two or more variables or sets of variables predict the outcome similarly well, both might not reach the significance criterion as neither can assert itself against the other(s). Their predictive power for the outcome variable is not impaired by this, which is why the total $R^{2}$ is significant. With regard to the standardized $\beta$-coefficients, phonological awareness, morphological fluency and rapid naming seem to be the most promising candidates for predictors for word reading fluency in fourth grade.

In addition to our main analyses, we conducted two supplementary analyses for a better interpretation of the data. Regarding research question three, that is for testing whether morphological awareness is a stronger predictor of literacy variables in later grades, we conducted additional regression analyses on our reading and spelling variables across Grades 2-4. For this, predictor and criterion variables were z-transformed within grades. Analyses followed a step-wise procedure. In step one, we entered age, phonological awareness, rapid naming, verbal memory, vocabulary, the pseudoword cloze task and morphological fluency as predictors, that is the same predictors we used in the original regression analyses. In step two, we introduced two interaction terms: pseudoword cloze task x grade level and morphological fluency $\mathrm{x}$ grade level. Finally, we compared the two models per outcome variable using ANOVA. For each literacy variable, adjusted $R^{2}$ s were significant using the 
predictor variables in step one (all $p<.01$ ), mirroring the results from our original regressions per grade. However, for no literacy variable model fit improved when adding the interaction terms in step two (all $p>.05$ ). In addition, all interactions were not significant (all $p>.05$ ).

Because we observed a high relevance of phonological awareness in our analyses until Grade 4, which is not in accordance with some previous studies in German (Görgen et al., 2021; Moll et al., 2009, 2014), we additionally tested whether phonological awareness is less associated with literacy in higher grades. Using the z-standardized variables introduced above, we conducted regression analyses in the combined sample with phonological awareness and the interaction between grade level and phonological awareness as predictors. In none of our regressions on literacy variables, the interaction term became significant (all $p>.05$ ), signifying that the respective magnitudes of the relationships between phonological awareness and the different literacy skills were comparable between grades.

\section{Discussion}

This study adds to the existing literature on the relationship between morphological awareness and literacy skills in three important ways: First, we analysed the relationship of morphological awareness with both reading and spelling in German to add insights into the role of orthographic transparency within a rather transparent, but asymmetric language. Second, we controlled for phonological processing variables and vocabulary to gauge the unique relationship of morphological awareness with literacy skills next to these variables in German. Third, we conducted this study cross-sectionally in Grades 2, 3 and 4 to test whether the relationship between morphological awareness and literacy skills is stronger in children with higher literacy proficiency.

In the current study, an oral pseudoword cloze task, in which pseudowords were embedded into real word sentences, was used to test children's ability to form German inflections, derivations and compounds in a pseudoword context. The ability to produce derivations and compounds of given real words was addressed with an oral morphological fluency task. Using factor analyses, morphological awareness as measured in the current study turned out to be a two-dimensional construct with one facet tapping the ability to apply morphological changes to pseudowords and one facet tapping quick word formation skills. As no German study previously analysed the factor structure of morphological awareness tasks, results are discussed in relation to English studies using a factor-analytic approach on morphological awareness. These studies found that morphological awareness skills of fourth grade (Muse, 2005) and college students (Wilson-Fowler, 2011) measured with various morphological awareness tasks converge to one single morphological awareness factor. The facets we found differ from each other with respect to three components: speed, useable context information and familiarity of the target word (real word vs. pseudoword). In the studies by Muse (2005) and Wilson-Fowler (2011) items also covered different levels of context information and both real words and pseudowords, but none of the items had a speed component. Therefore, it is likely that the 
speed component is the critical distinction between the facets we found in the current study. Yet, differences between English and German could also account for the observed disparities.

\section{How is morphological awareness related to different literacy competencies in the asymmetric orthography of German?}

Both our facets of morphological awareness were related to reading and spelling skills in second, third and fourth grade. The observed relationship between morphological awareness and literacy skills is in line with previous German research on primary school children (Görgen et al., 2021; Kargl \& Landerl, 2018; Kargl et al., 2018; Klassert et al., 2018; Volkmer et al., 2019), but extends previous findings insofar as we showed that there is more than one facet of morphological awareness that can be tested reliably in German primary school children. Furthermore, as we used a purely oral presentation and response format, our results show that relations between morphological awareness and literacy skills in German primary school children hold when the morphological awareness tasks make absolutely no reference to children's reading and spelling skills (see also Klassert et al., 2018).

Our correlational data suggest that different facets of morphological awareness are differentially related to reading and spelling. In the current study, all correlations between the pseudoword cloze task and literacy skills were significant in all grades, whereas only between three and six of seven correlations between morphological fluency and literacy variables were significant in Grades 2 to 4 . This indicates that the sheer ability to recognize and manipulate morphological structures might be more important for reading and spelling than the speed by which morphological structures are handled.

As German is orthographically more consistent for reading than for spelling, we expected that relations between morphological awareness and spelling would be stronger than those between morphological awareness and reading. Nevertheless, correlations of morphological awareness with spelling $(.13 \leq r \leq .48)$ and with reading $(.07 \leq r \leq .47)$ were of comparable height. Although being in contrast to theoretical considerations, the results are in line with most previous findings within the orthographically asymmetric languages German (Fink et al., 2012; Volkmer et al., 2019; but see Görgen et al., 2021) and Greek (Desrochers et al., 2018; Pittas \& Nunes, 2014). One reason for this observation might lie in how proficient children are in applying morphological strategies. Klassert et al. (2018) found that although third graders made more use of morphological spelling strategies than first and second graders did, they did not make less spelling errors. The authors inferred that German primary school children have difficulties with the application of morphological spelling strategies and that morphological strategy use does not immediately lead to better spelling performances but, at the beginning of strategy use, to more diverse mistakes. Observations of morphological spelling strategy use in the current study are in line with these findings. We found that proficiency in morphological spelling strategy was lower in second grade, in which children used on average a morphological spelling strategy for $52 \%$ of the words analysed in this context in 
the HSP, than in third (68\%) and fourth grade (74\%). The percentages imply that with increasing grade level children increasingly make use of morphological units in spelling; yet, morphological strategies are not fully acquired until the end of primary school. Therefore, morphological awareness might rise in importance for spelling skills in later school years when children become more proficient in the application of morphological strategies. This also means that a potential divergent importance of morphological awareness for spelling versus reading in asymmetric orthographies might become visible only later when school children can reliably make use of different strategies in spelling and in reading. Future studies should aim to clarify this open question by assessing children in higher grade levels.

\section{Does morphological awareness uniquely predict literacy skills above and beyond other language-related cognitive skills in German?}

When taking other language-related cognitive variables into account, we found that morphological awareness did not explain additional variance in spelling and in reading beyond phonological awareness and rapid naming. This result is in contrast to previous findings for German (Görgen et al., 2021; Volkmer et al., 2019). The reason might be a methodological difference. While we used a purely oral presentation and response format in our morphological awareness tasks, both former German studies used a written presentation (Görgen et al., 2021) and response format (Volkmer et al., 2019), respectively. Although Volkmer et al. (2019) did not take spelling errors into account, the requirement to express responses in writing could have influenced the observed relationship between morphological awareness and spelling. Likewise, the requirement to read morphological awareness items in the study by Görgen and colleagues (2021) might have influenced the observed relations between morphological awareness and reading fluency. It also has to be noted that in the current study, morphological awareness variables and phonological awareness were in part highly correlated ( $r$ between .23 and .61 ), which might have prevented morphological awareness from explaining additional variance in literacy skills.

We observed a strong relation of phonological awareness with all reading and spellings skills in all grades ( $r$ between .44 and .74, i.e. explaining between 19 and $55 \%$ of variance, all $p<.01$ ). Additionally, in the regression analyses, phonological awareness was the most important predictor for literacy skills in all three grades. An interaction analysis revealed that the respective relationships between phonological awareness and literacy skills were of comparable height in second, third and fourth grade. These results demonstrate that until the end of Grade 4 phonological awareness is a unique and strong predictor of literacy skills. The associations between phonological awareness and literacy skills seem surprisingly strong in the light of the results of other cross-sectional studies with German-speaking primary school children using single tasks to measure phonological awareness (e.g. Görgen et al., 2021; Moll et al., 2009, 2014). They are, however, in line with other German crosssectional studies with second- to fourth graders using psychodiagnostic instruments or adaptations thereof measuring more than one facet of phonological awareness. These studies observed comparably high correlations of phonological awareness 
with reading of $.42 \leq r \leq .60$ and spelling of $.51 \leq r \leq .74$ (monolingual German sample in Limbird, 2007; Steinbrink et al., 2019; Stock et al., 2017).

But which additional factors might account for the relatively high correlations between phonological awareness and literacy in our study? Firstly, we cannot rule out the possibility that our participants (children with at least nearly two years of reading and spelling experience) used - besides phonological information - orthographic representations when solving the phonological awareness tasks. This is a general potential confound when measuring phonological awareness in children with reading and spelling experience (see also Bryant et al., 1990; Treiman \& Cassar, 1997). The fact that in the current study, the items used in the phonological awareness tasks consisted solely of real German words might, however, have aggravated potential tendencies for referring to the items' spelling, as an orthographic strategy for solving phonological awareness tasks is more often applied with words than with pseudowords (Stuart, 1990). Secondly, it is common to base early reading and spelling instruction on phoneme-grapheme-mappings in Germany (see Füssenich \& Löffler, 2005), for example by using initial sound tables (Bremerich-Vos \& Wendt, 2019; Bross, 2016; Hagemann, 2018). This phonological approach to literacy instruction might - at least for children from lower grades - be an explaining factor for the strong association we observed between phonological awareness and literacy. Thirdly, although children learning to read German move to more direct / lexical reading strategies during the first school years (Rau et al., 2014; Wimmer \& Goswami, 1994), and, as our own data document, are in principle able to use skilled (orthographic and morphological) spelling strategies in Grades 2 to 4 (see Table 1), alphabetic reading and spelling strategies might remain important due to the relatively high orthographic transparency of German. Indeed, in German, alphabetic reading strategies are more important than in the opaque English orthography. This was found for children in their first years of schooling (Wimmer \& Goswami, 1994), as well as for adults (Ziegler et al., 2001). Interestingly, concerning spelling strategies, an in-depth analysis of the orthographic and morphological spelling errors of our Grade 4 sample showed that the vast majority of these spelling errors (87\%, i.e. 574 of the 663 errors that were categorised) stemmed from the application of an alphabetic spelling strategy. ${ }^{1}$ Thus, reading and spelling strategies capitalising

\footnotetext{
${ }^{1}$ We re-analysed in the fourth-grade children of our sample those word parts used in the HSP (spelling test) to identify orthographic and morphological spelling strategies that were not spelled correctly. Errors occurred in 82 of 85 children. Children committed between 1 and 18 orthographic spelling errors, and between 1 and 14 morphological spelling errors. Altogether, 354 orthographic and 326 morphological spelling errors were rated independently by the two authors with respect to the question, whether, alternatively, an alphabetic spelling strategy was applied (yes vs. no; inter-rater reliability $90 \%$, inconsistencies resolved by joint judgement in further $7 \%$ of the cases). Alphabetic spelling strategies were applied, when phoneme-grapheme-mappings resulting in incorrect spellings instead of orthographic or morphological regularities were used to spell the relevant word parts. Examples for the use of an alphabetic instead of an orthographic spelling strategy are the following: In the German word Rollschuhe [Eng. rollerblades] the double consonant $<11>$ is an orthographic marking of the preceding short vowel $\mathrm{/}$. The double consonant is pronounced as a single phoneme /1/. Thus, spelling the word as Rolschuhe indicates the use of an alphabetic spelling strategy for this word part. In the same word, the $<\mathrm{h}>$ following the $<\mathrm{u}>$ (Rollschuhe) is an orthographic marking of the long vowel /u:/, which is not spoken ("silent h"). Writing down the word as Rollschue, that is leaving out the silent h, shows that an alpha-
} 
on grapheme-phoneme and phoneme-grapheme-mappings, respectively, might remain relatively important until the end of primary school in German. This, in turn, might be another factor explaining the strong association of phonological awareness with reading and spelling in our sample.

In this context, it may be viewed as a surprising result of our study that phonological awareness was not only strongly related to alphabetic spelling strategies, but also to orthographic and morphological spelling strategies. We offer the following explanation: Phonemic awareness (as measured in the current study) helps children to establish spelling strategies based on phoneme-grapheme mappings. These alphabetic spelling strategies in turn allow to build up word-specific orthographic representations in the mental lexicon which are a foundation for skilled spelling strategies that are needed for orthographically correct spelling (see Caravolas et al., 2001; Moll et al., 2014). Additionally, although stage models of literacy acquisition specify the importance of orthographic and morphological strategies for skilled reading and spelling (Frith, 1985, 1986; Varnhagen, 1995), there is evidence that both children and adults have difficulty with applying morphological strategies on novel words (Kemp \& Bryant, 2003; Kemp et al., 2017). That is, the importance of morphological awareness might vary with the ability to capitalise on morphological strategies. Based on stage models of literacy development, we assume that the relevance of morphological awareness continues to unfold beyond primary school for skilled reading and spelling.

\section{Is the relationship between morphological awareness and literacy skills stronger in children who are more literacy-proficient?}

The results of our regression analyses did not indicate a stronger relationship of morphological awareness with literacy skills for children with higher literacy proficiency, that is in later primary school years, as adding interaction terms of morphological awareness variables with grade level to the regression models did not improve model fit as compared to a simple additive model. Compared to results for the English language, our results are in line with a meta-analysis by Lee (2011), but

\footnotetext{
Footnote 1 (continued)

betic spelling strategy is applied for this word part. Examples for the use of an alphabetic instead of a morphological spelling strategy are the following: Firstly, due to syllable-final devoicing in German, the grapheme $<\mathrm{b}\rangle$ in the word Staubsauger [Eng. vacuum cleaner; literally "dust-sucker"] is pronounced as $/ \mathrm{p} /$. The correct spelling has to be deduced by using a morphological spelling strategy (i.e. inferring the meaning of the first syllable Staub). Spelling the word as Staupsauger indicates the use of an alphabetic spelling strategy for this word part. Secondly, in the word Bankräuber [Eng. bank robber], the diphthong is pronounced as /or/. Two realizations of this diphthong in spelling are principally possible: < äu > and <eu > . In the word Bankräuber, the realization <äu > is correct, as the word Räuber is derived from the verb rauben [eng. to rob]. Thus, spelling the word as Bankreuber shows that an alphabetic instead of a morphological spelling strategy is applied for the relevant word part. Of the 663 errors that were interpretable, in $87 \%$ of the instances an alphabetic instead of an orthographic/ morphological strategy was applied (alphabetic instead of orthographic: 90\%, alphabetic instead of morphological: $83 \%$ ).
} 
are, concerning reading fluency, in contrast to a meta-analysis by Ruan et al. (2018). However, Ruan et al. (2018) covered a much wider age range and it is possible that increases in the strength of the relationship between morphological awareness and literacy skills become apparent only after primary school years. For German, the recent study by Görgen et al. (2021) indicated a stronger unique contribution of morphological awareness for spelling in Grade 4 than in Grade 3, while, the current study could not confirm this finding. Future studies with German school children should include a wider range of school grades.

Yet, in Grade 4, six out of seven correlations of morphological fluency with literacy skills were significant (the non-significant correlation being the one between morphological fluency and alphabetic spelling strategy), while in Grades 2 and 3 only four and three correlations, respectively, were significant. This finding might be indicative of an increasing importance of morphological fluency. Our tentative assumption is that the speed with which morphological structures can be detected and manipulated becomes the more important the more literacy competent children are. Future studies could test this hypothesis by comparing beginning and skilled readers and spellers.

\section{Limitations and future research prospects}

This study has to be interpreted in light of its limitations. One of the main strengths of this study, the assessment of multiple cognitive and literacy variables, is also one of its main limitations. The relatively high number of study variables in comparison with the number of participants caused an accumulation of both $\alpha$ - and $\beta$-error probabilities. Therefore, some observed relationships might in fact be negligible while others remained undetected. This is specifically apparent for the control variable rapid naming. Based on former studies, we expected rapid naming to be particularly relevant for reading fluency (Ennemoser et al., 2012; Landerl, 2017; 2008; Moll et al., 2012). Indeed, in the simple correlation analyses, rapid naming was related to reading fluency, but in regression analyses, it was not a unique predictor in most instances. Yet, we are convinced our results contribute to the understanding of the relationship between morphological awareness and literacy skills because the overall picture manifested in several repeated observations: We found correlational relationships between morphological awareness and all literacy variables in all three grades but none of the morphological awareness variables could assert itself against phonological processing variables and vocabulary in regression analyses. Nonetheless, it should be explored whether future studies can replicate the findings, for example with students experiencing different approaches to literacy instruction.

Another point to be considered regards the in part strong relationships between some of the predictor variables, like the correlations of phonological awareness, morphological awareness and verbal memory. Intercorrelations between different cognitive variables might be due to the fact that some of the applied tasks share certain demands. For example, children needed verbal memory skills for solving phonological and morphological awareness tasks by holding phonological information present while manipulating the test word. This was no mistake in the design of 
the task, but represents that several cognitive variables go hand-in-hand in language processing.

Reliability was lower than expected for our vocabulary measure. This might be due to the adaptation from a written to an oral + written presentation format. This adaptation was applied to minimise potential confounding effects with other variables. Yet, considering difficulty indices, some of the items were too easy and did not differentiate between students. Our adaptation and the considerably low reliability might have caused relationships between vocabulary and other measures to be estimated incorrectly. Specifically, we cannot fully rule out that reading skills influenced the vocabulary score as children could read along while the items were presented verbally. If this was the case, this would lead to an overestimation of the relationships between vocabulary and reading skills. Nonetheless, vocabulary was no unique predictor in our regression analyses indicating that we did not substantially overestimate the relationships in question. For future studies, which might want to apply unadapted measures of vocabulary with more items, it might be of interest that systematically for all four spelling measures, vocabulary and spelling skills were associated in Grades 2 and 3, but not in Grade 4 (see also Berendes et al., 2010).

This study focused on relationships of morphological awareness with literacy skills. Although controlling for a range of language-related cognitive variables, there are further cognitive variables connected to literacy skills. One such variable is orthographic awareness (Berninger et al., 2010). In this context, morphology might be the bridge between phonology and orthography in heard/spoken and read/ written words (Bahr et al., 2020). Recent studies suggest that orthographic knowledge is related to reading and spelling in German school children (Zarić \& Nagler, 2021; Zarić et al., 2021). Therefore, we consider the interplay between phonological awareness, morphological awareness and orthographic awareness, and the study of their relative contribution to literacy skills in German as a valuable future research direction.

Finally, this study used a cross-sectional, correlational design, which does not allow conclusions on causation. Indeed, previous English studies found that the relationship between morphological awareness and literacy variables is most likely bidirectional (Deacon et al., 2013; Kuo \& Anderson, 2006), an observation that could not be represented with the chosen design. We chose our cross-sectional design because we wanted to gain an overview on different relevant aspects of the relationship of morphological awareness and literacy skills, such as the influence of literacy proficiency, other language-related variables and orthographic transparency. A valuable direction for future research would be to collect evidence on the development of the relationship between morphological awareness and literacy skills in German in a longitudinal study. 


\section{Conclusion}

Our study conducted with German primary school children confirms that morphological awareness is an important correlate of literacy in transparent orthographies. There was, however, no indication that over the primary school years, morphological awareness is more strongly related to spelling than to reading in a language that is less transparent for spelling than for reading. When accounting for phonological processing variables and vocabulary, morphological awareness was in none of the three grades investigated a unique predictor of literacy skills. This might indicate that in a transparent orthography, other language-related variables, especially phonological awareness, can remain an important base of primary school literacy skills after the early steps of reading and spelling acquisition have been mastered. This tendency might be aggravated by a phonological approach to reading and spelling instruction. Evidence for a stronger relationship between morphological awareness and literacy skills in children with higher literacy competency was limited. Yet, results indicated that morphological fluency as a facet of morphological awareness might gain importance with increasing literacy competency. Although still much research is needed with respect to relations between morphological awareness and literacy, this study gives valuable insights into several questions on morphological awareness and its relation to primary school literacy skills in a transparent, but asymmetric orthography.

Acknowledgements Permission to work with the respective items was kindly provided by the pertinent right holders. We thank the publishing house Hogrefe who granted permission to use the adapted material of the HSET. We also thank Prof. Dr. Andreas Fink, Mag. Dr. Reinhard Kargl and Mag. Christian Purgstaller who provided unpublished material from the TMB and permitted us to use their items for this study. Further, we thank Prof. Dr. Sascha Schroeder and Dr. Jana Hasenäcker who permitted us to use their items on compounding and Prof. Dr. Sascha Schroeder for providing access to unpublished material from the childLex database. The educational authority for the region of central Thuringia (Staatliches Schulamt Mittelthüringen) gave permission for conducting this study in local schools. We thank all schools, teachers, parents and students who participated in this study. We also thank Julia Göldel, AnnaMaria Mager, Katharina Ockl, Alexa Ott and Betina Turbi de Hilmann for their support in data collection and data processing. Many thanks are also due to three anonymous reviewers for their helpful comments and suggestions to earlier drafts of this article.

Funding Open Access funding enabled and organized by Projekt DEAL. Testing material was in part financed by the "Nachwuchskolleg Sprachbeherrschung", an interdisciplinary university-funded qualification programme for doctoral and postdoctoral scientists working in the field of language research at the University of Erfurt.

Data availability Data not available because of directions by the educational authority for the region of central Thuringia (Staatliches Schulamt Mittelthüringen) for data usage for this study. Material not available because of test protection requirements (cf. Diagnostik- und Testkuratorium der Föderation Deutscher Psychologenvereinigungen, 2019) as adapted material was originally constructed by other authors.

Code availability Not applicable.

\section{Declarations}

Conflict of interest The authors declare that the research was conducted in the absence of any commercial or financial relationships that could be construed as a potential conflict of interest. 
Ethical approval This study was approved by the educational authority for the region of central Thuringia (Staatliches Schulamt Mittelthüringen). The assessment of this study comprised reviews on ethical standards and data privacy requirements for conducting studies with schoolchildren in schools and during lessons. Additional approval by an ethics committee was not required in compliance with institutional and federal (Thuringian) guidelines and regulations.

Consent to participate School staff, parents and schoolchildren themselves were informed about the aim, methods and procedures of this study. Written informed consent was obtained from the parents of participating children.

Consent for publication Not applicable.

Open Access This article is licensed under a Creative Commons Attribution 4.0 International License, which permits use, sharing, adaptation, distribution and reproduction in any medium or format, as long as you give appropriate credit to the original author(s) and the source, provide a link to the Creative Commons licence, and indicate if changes were made. The images or other third party material in this article are included in the article's Creative Commons licence, unless indicated otherwise in a credit line to the material. If material is not included in the article's Creative Commons licence and your intended use is not permitted by statutory regulation or exceeds the permitted use, you will need to obtain permission directly from the copyright holder. To view a copy of this licence, visit http://creativecommons.org/licen ses/by/4.0/.

\section{References}

Abteilung Automatische Sprachverarbeitung (2011). Deutsches Nachrichten-Korpus basierend auf Texten gecrawlt 2011: Korpus: German (deu_newscrawl_2011). Retrieved from http://wortschatz.unileipzig.de/de.

Apel, K. (2014). A comprehensive definition of morphological awareness: Implications for assessment. Topics in Language Disorders, 34(3), 197-209.

Bahr, R. H., Silliman, E. R., \& Berninger, V. W. (2020). Derivational morphology bridges phonology and orthography: insights into the development of word-specific spellings by superior, average, and poor spellers. Language, Speech, and Hearing Services in Schools, 51(3), 640-654. https://doi.org/ 10.1044/2020_LSHSS-19-00090

Berendes, K., Schnitzler, C. D., Willmes, K., \& Huber, W. (2010). Die Bedeutung von Phonembewusstheit und semantisch-lexikalischen Fähigkeiten für Schriftsprachleistungen in der Grundschule. Sprache Stimme Gehör. https://doi.org/10.1055/s-0029-1246203

Berko, J. (1958). The child's learning of English morphology. Word, 14(2-3), 150-177.

Berlin-Brandenburgische Akademie der Wissenschaften (n.d.). DWDS - Digitales Wörterbuch der deutschen Sprache: Textkorpora. Retrieved from https://www.dwds.de/.

Berninger, V. W., Abbott, R. D., Nagy, W. E., \& Carlisle, J. (2010). Growth in phonological, orthographic, and morphological awareness in grades 1 to 6. Journal of Psycholinguistic Research, 39(2), 141-163. https://doi.org/10.1007/s10936-009-9130-6

Borgwaldt, S. R., Hellwig, F. M., \& de Groot, A. M. (2004). Word-initial entropy in five languages: Letter to sound, and sound to letter. Written Language \& Literacy, 7(2), 165-184. https://doi.org/10. 1075/w11.7.2.03bor

Bremerich-Vos, A., \& Wendt, H. (2019). Zur Nutzung von Laut- bzw. Anlauttabellen im Deutschunterricht der Grundschule. Zeitschrift Für Angewandte Linguistik, 70(1), 19-36. https://doi.org/10. 1515/zfal-2019-2015

Bross, F. (2016). Initial sound tables: blessing or curse for learning to read and write? translation of the german article: Anlauttabellen - Segen oder Fluch im Schriftspracherwerb. Zeitschrift Für Germanistik \& Literatur, 30, 108-117.

Bryant, P., Maclean, M., \& Bradley, L. (1990). Rhyme, language, and children's reading. Applied Psycholinguistics, 11, 237-252. 
Caravolas, M., Hulme, C., \& Snowling, M. J. (2001). The foundations of spelling ability: Evidence from a 3-year longitudinal study. Journal of Memory and Language, 45(4), 751-774. https://doi.org/10. 1006/jmla.2000.2785

Carlisle, J. F. (1995). Morphological awareness and Early Reading Achievement. In L. B. Feldman (Ed.), Morphological aspects of language processing (pp. 189-209). Lawrence Erlbaum Associates Inc.

Carlisle, J. F., \& Fleming, J. (2003). Lexical processing of morphologically complex words in the elementary years. Scientific Studies of Reading, 7(3), 239-253. https://doi.org/10.1207/S1532799XS SR0703_3

Carroll, J. M., Snowling, M. J., Hulme, C., \& Stevenson, J. (2003). The development of phonological awareness in preschool children. Developmental Psychology, 39(5), 913-923. https://doi.org/10. 1037/0012-1649.39.5.913

Casalis, S., Colé, P., \& Sopo, D. (2004). Morphological awareness in developmental dyslexia. Annals of Dyslexia, 54(1), 114-138.

Casalis, S., \& Louis-Alexandre, M.-F. (2000). Morphological analysis, phonological analysis and learning to read French: A longitudinal study. Reading and Writing, 12, 303-335.

Deacon, S. H., Benere, J., \& Pasquarella, A. (2013). Reciprocal relationship: Children's morphological awareness and their reading accuracy across grades 2 to 3. Developmental Psychology, 49(6), 1113-1126. https://doi.org/10.1037/a0029474

Deacon, S. H., Parrila, R., \& Kirby, J. R. (2008). A review of the evidence on morphological processing in dyslexics and poor readers: a strength or weakness? In G. Reid, A. Fawcett, F. R. Manis, \& L. S. Siegel (Eds.), The SAGE handbook of dyslexia (pp. 212-237). Sage.

Desrochers, A., Manolitsis, G., Gaudreau, P., \& Georgiou, G. (2018). Early contribution of morphological awareness to literacy skills across languages varying in orthographic consistency. Reading and Writing, 31(8), 1695-1719. https://doi.org/10.1007/s11145-017-9772-y

Diagnostik- und Testkuratorium der Föderation Deutscher Psychologenvereinigungen (2019). Tests in Lehre und Forschung: Informationen zum Testschutz und zum Urheberrecht. Retrieved from https://www.dgps.de/fileadmin/user_upload/foederation/dtk_tests_in_lehre_und_forschung.pdf

Donovan, J. L., \& Marshall, C. R. (2016). Comparing the verbal self-reports of spelling strategies used by children with and without dyslexia. International Journal of Disability, Development and Education, 63(1), 27-44. https://doi.org/10.1080/1034912X.2015.1111302

Dudenredaktion (Ed.) (2016). Duden - Deutsche Sprache in 12 Bänden: Vol. 4. Die Grammatik: Unentbehrlich für richtiges Deutsch (9th ed.). Berlin: Dudenverlag.

Elsen, H. (2014). Grundzüge der Morphologie des Deutschen (2nd ed.). De Gruyter Studium. Berlin: de Gruyter Mouton.

Ennemoser, M., Marx, P., Weber, J., \& Schneider, W. (2012). Spezifische Vorläuferfertigkeiten der Lesegeschwindigkeit, des Leseverständnisses und des Rechtschreibens. Zeitschrift Für Entwicklungspsychologie Und Pädagogische Psychologie, 44(2), 53-67. https://doi.org/10.1026/0049-8637/ $\mathrm{a} 000057$

Esser, G., \& Wyschkon, A. (2010). Potsdam-Illinois Test für Psycholinguistische Fähigkeiten (P-ITPA). Hogrefe.

Fejzo, A. (2016). The contribution of morphological awareness to the spelling of morphemes and morphologically complex words in French. Reading and Writing, 29(2), 207-228. https://doi.org/10. $1007 / \mathrm{s} 11145-015-9586-8$

Field, A. (2018). Discovering statistics using IBM SPSS statistics (5th ed.). Sage.

Fink, A., Pucher, S., Reicher, A., Purgstaller, C., \& Kargl, R. (2012). Entwicklung eines Tests zur Erfassung der morphematischen Bewusstheit: Erste Daten. Empirische Pädagogik, 26(4), 423-451.

Fleischer, W., \& Barz, I. (2012). Wortbildung der deutschen Gegenwartssprache (4., vollst. überarb. Aufl.). Studienbuch. Berlin: De Gruyter.

Frith, U. (1985). Beneath the Surface of Developmental Dyslexia. In K. E. Patterson, J. C. Marshall, \& M. Coltheart (Eds.), Surface Dyslexia: Neuropsychological and Cognitive Studies of Phonological Reading (pp. 301-330). Erlbaum.

Frith, U. (1986). A developmental framework for developmental dyslexia. Annals of Dyslexia, 36(1), 67-81. https://doi.org/10.1007/BF02648022

Füssenich, I., \& Löffler, C. (2005). Schriftspracherwerb - Einschulung, Erstes und Zweites Schuljahr. Ernst Reinhardt Verlag.

Gallmann, P. (2016). Nomen: Pluralformen. Jena. Retrieved from http://www.personal.uni-jena. de/ x1gape/Wort/Wort_Nomen_Pluralform.pdf. 
Görgen, R., de De Simone, E., Schulte-Körne, G., \& Moll, K. (2021). Predictors of reading and spelling skills in German: The role of morphological awareness. Journal of Research in Reading, 44(1), 210-227. https://doi.org/10.1111/1467-9817.12343

Goswami, U. (1988). Children's use of analogy in learning to spell. British Journal of Developmental Psychology, 6(1), 21-33. https://doi.org/10.1111/j.2044-835X.1988.tb01077.x

Goswami, U., \& Bryant, P. (1990). Phonological skills and learning to read. Lawrence Erlbaum Associates.

Grimm, H., \& Schöler, H. (1991). H-S-E-T: Heidelberger Sprachentwicklungstest (2nd ed.). Hogrefe.

Gustafsson, J.-E., Nilsen, T., \& Hansen, K. Y. (2018). School characteristics moderating the relation between student socio-economic status and mathematics achievement in grade 8 . Evidence from 50 countries in TIMSS 2011. Studies in Educational Evaluation, 57, 16-30. https://doi.org/10.1016/j. stueduc.2016.09.004

Hagemann, J. (2018). (An-)Lauttabellen und silbenbasierte Lehrwerke im Deutschunterricht der Primarstufe. Glottotheory, 9(1), 1-27. https://doi.org/10.1515/glot-2018-0003

Haider, G., \& Böck, M. (2001). Pisa 2000. Beiträge zur vergleichenden Schulforschung: 3, [3]. Innsbruck, Wien, München, Bozen: Studien-Verl.

Hasenäcker, J., \& Schroeder, S. (2017). Aufgaben zur Kompositabildung. Max Planck Institute for Human Development.

Kargl, R., \& Landerl, K. (2018). Beyond phonology: The role of morphological and orthographic spelling skills in German. Topics in Language Disorders, 38(4), 272-285. https://doi.org/10.1097/TLD. 0000000000000165

Kargl, R., Wendtner, A., Purgstaller, C., \& Fink, A. (2018). Der Einfluss der morphematischen Bewusstheit auf die Rechtschreibleistung. Lernen Und Lernstörungen, 7(1), 45-54. https://doi.org/10. 1024/2235-0977/a000202

Kemp, N., \& Bryant, P. (2003). Do beez buzz? Rule-based and frequency-based knowledge in learning to spell plural -s. Child Development, 74(1), 63-74. https://doi.org/10.1111/1467-8624.00521

Kemp, N., Mitchell, P., \& Bryant, P. (2017). Simple morphological spelling rules are not always used: Individual differences in children and adults. Applied Psycholinguistics, 38(5), 1071-1094. https:// doi.org/10.1017/S0142716417000042

Kirby, J. R., Deacon, S. H., Bowers, P. N., Izenberg, L., Wade-Woolley, L., \& Parrila, R. (2012). Children's morphological awareness and reading ability. Reading and Writing, 25(2), 389-410. https:// doi.org/10.1007/s11145-010-9276-5

Kirby, J. R., Desrochers, A., Roth, L., \& Lai, S. S. V. (2008). Longitudinal predictors of word reading development. Canadian Psychology/psychologie Canadienne, 49(2), 103-110. https://doi.org/10. 1037/0708-5591.49.2.103

Klassert, A., Bormann, S., Festman, J., \& Gerth, S. (2018). Rechtschreibung von Konsonantenclustern und morphologische Bewusstheit bei Grundschüler_innen. Zeitschrift Für Entwicklungspsychologie Und Pädagogische Psychologie, 50(3), 115-125. https://doi.org/10.1026/0049-8637/a000193

Kleinke, K., Schlüter, E., \& Christ, O. (2017). Strukturgleichungsmodelle mit Mplus: Eine praktische Einführung (2., aktualisierte und (erweiterte). Walter de Gruyter.

König, E., \& Gast, V. (2012). Understanding English-German contrasts (3rd ed.). Grundlagen der Anglistik und Amerikanistik: Vol. 29. Berlin: E. Schmidt.

Kotulková, V. (2004). Deutsche Determinativkomposita und ihre Entsprechungen im Tschechischen (Dissertation). Julius-Maximilians-Universität.

Kuo, L., \& Anderson, R. C. (2006). Morphological awareness and learning to read: A cross-language perspective. Educational Psychologist, 41(3), 161-180. https://doi.org/10.1207/s15326985ep4103_3

Landerl, K. (2017). Learning to Read German. In L. T. Verhoeven \& C. A. Perfetti (Eds.), Learning to read across languages and writing systems (pp. 299-322). Cambridge University Press.

Landerl, K., \& Wimmer, H. (2008). Development of word reading fluency and spelling in a consistent orthography: An 8-year follow-up. Journal of Educational Psychology, 100(1), 150-161. https:// doi.org/10.1037/0022-0663.100.1.150

Lee, S. (2011). The relationship between morphological awareness and literacy outcomes of elementary students: A meta-analysis study (Dissertation). University of Oregon.

Lenhard, W., Lenhard, A., \& Schneider, W. (2017). Ein Leseverständnistest für Erst- bis Siebtklässler Version II: ELFE-II. 3 (korrigierte). Hogrefe Verlag GmbH \& Co. KG.

Limbird, C. K. (2007). Phonological processing, verbal abilities, and second language literacy development among bilingual Turkish children in Germany (Dissertation). Free University of Berlin, Berlin. https://doi.org/10.17169/REFUBIUM-9364 
May, P. (2013). Hamburger Schreib-Probe: HSP ...; [zur Erfassung der grundlegenden Rechtschreibstrategien mit der Hamburger Schreibprobe] (Neunormierung 2012, 1. Aufl.). [Stuttgart], Stuttgart: VPM, Verl. für Pädag. Medien; Klett.

May, P., \& Bennöhr, J. (2013). KEKS: Kompetenzerfassung in Kindergarten und Schule. Handbuch - Konzept, theoretische Grundlagen und Normierung (1st ed.). Cornelsen Schulverlag GmbH.

McBride-Chang, C. (2004). Children's literacy development. Texts in developmental psychology. Hodder Education Publishers.

McBride-Chang, C., Wagner, R. K., Muse, A. E., Chow, B.W.-Y., \& Shu, H. (2005). The role of morphological awareness in children's vocabulary acquisition in English. Applied Psycholinguistics, 26(03), 415-435. https://doi.org/10.1017/S014271640505023X

McCutchen, D., \& Stull, S. (2015). Morphological awareness and children's writing: Accuracy, error, and invention. Reading and Writing, 28(2), 271-289. https://doi.org/10.1007/ s11145-014-9524-1

Moll, K., Fussenegger, B., Willburger, E., \& Landerl, K. (2009). Ran is not a measure of orthographic processing. Evidence from the asymmetric German orthography. Scientific Studies of Reading, 13(1), 1-25. https://doi.org/10.1080/10888430802631684

Moll, K., \& Landerl, K. (2014). SLRT-II: Lese- und Rechtschreibtest. Weiterentwicklung des Salzburger Lese- und Rechtschreibtests (SLRT) (2nd ed.). Verlag Hans Huber.

Moll, K., Ramus, F., Bartling, J., Bruder, J., Kunze, S., Neuhoff, N., \& Landerl, K. (2014). Cognitive mechanisms underlying reading and spelling development in five European orthographies. Learning and Instruction, 29, 65-77. https://doi.org/10.1016/j.learninstruc.2013.09.003

Moll, K., Wallner, R., \& Landerl, K. (2012). Kognitive Korrelate der Lese-, Leserechtschreib- und der Rechtschreibstörung. Lernen Und Lernstörungen, 1(1), 7-19. https://doi.org/10.1024/22350977/a000002

Müller, K., \& Brady, S. (2001). Correlates of early reading performance in a transparent orthography. Reading and Writing, 14(7/8), 757-799. https://doi.org/10.1023/A:1012217704834

Muse, A. E. (2005). The Nature of Morphological Knowledge (Dissertation). Florida State University.

Muthén, L. K., \& Muthén, B. (2018). MPlus (Version 8) [Computer software]. Los Angeles, Calif.

Nagy, W. E., Berninger, V. W., \& Abbott, R. D. (2006). Contributions of morphology beyond phonology to literacy outcomes of upper elementary and middle-school students. Journal of Educational Psychology, 98(1), 134-147. https://doi.org/10.1037/0022-0663.98.1.134

Nunes, T., Bryant, P., \& Bindman, M. (1997). Morphological spelling strategies: Developmental stages and processes. Developmental Psychology, 33(4), 637-649. https://doi.org/10.1037/ 0012-1649.33.4.637

Petermann, F., \& Daseking, M. (2015). Zürcher Lesetest - II: ZLT-II. Weiterentwicklung des Zürcher Lesetests (ZLT) von Maria Linder und Hans Grissemann, 3., überarbeitete Auflage mit erweiterten Normen. Bern: Verlag Hans Huber.

Pittas, E., \& Nunes, T. (2014). The relation between morphological awareness and reading and spelling in Greek: A longitudinal study. Reading and Writing, 27(8), 1507-1527. https://doi.org/10. 1007/s11145-014-9503-6

Quémart, P., \& Casalis, S. (2017). Morphology and spelling in French students with dyslexia: The case of silent final letters. Annals of Dyslexia, 67(1), 85-98. https://doi.org/10.1007/ s11881-016-0133-3

Rau, A. K., Moeller, K., \& Landerl, K. (2014). The transition from sublexical to lexical processing in a consistent orthography: An eye-tracking study. Scientific Studies of Reading, 18(3), 224-233. https://doi.org/10.1080/10888438.2013.857673

Robertson, E. K., \& Deacon, S. H. (2019). Morphological awareness and word-level reading in early and middle elementary school years. Applied Psycholinguistics, 40(04), 1051-1071. https://doi.org/10. 1017/S0142716419000134

Robertson, E. K., Joanisse, M. F., Desroches, A. S., \& Terry, A. (2013). Past-tense morphology and phonological deficits in children with dyslexia and children with language impairment. Journal of Learning Disabilities, 46(3), 230-240. https://doi.org/10.1177/0022219412449430

Ruan, Y., Georgiou, G. K., Song, S., Li, Y., \& Shu, H. (2018). Does writing system influence the associations between phonological awareness, morphological awareness, and reading? A Meta-Analysis. Journal of Educational Psychology, 110(2), 180-202. https://doi.org/10.1037/edu0000216

Schmalz, X., Marinus, E., Coltheart, M., \& Castles, A. (2015). Getting to the bottom of orthographic depth. Psychonomic Bulletin \& Review, 22(6), 1614-1629. https://doi.org/10.3758/ s13423-015-0835-2 
Schreiber, J. B., Nora, A., Stage, F. K., Barlow, E. A., \& King, J. (2006). Reporting structural equation modeling and confirmatory factor analysis results: A review. The Journal of Educational Research, 99(6), 323-338. https://doi.org/10.3200/JOER.99.6.323-338

Schroeder, S., Würzner, K.-M., Heister, J., Geyken, A., \& Kliegl, R. (2015). Childlex: A lexical database of German read by children. Behavior Research Methods, 47(4), 1085-1094. https://doi.org/10. 3758/s13428-014-0528-1

Sénéchal, M., Basque, M. T., \& Leclaire, T. (2006). Morphological knowledge as revealed in children's spelling accuracy and reports of spelling strategies. Journal of Experimental Child Psychology, 95(4), 231-254. https://doi.org/10.1016/j.jecp.2006.05.003

Seymour, P. H. K., Aro, M., \& Erskine, J. M. (2003). Foundation literacy acquisition in European orthographies. British Journal of Psychology, 94(2), 143-174. https://doi.org/10.1348/000712603321661 859

Sprenger-Charolles, L., Siegel, L. S., Béchennec, D., \& Serniclaes, W. (2003). Development of phonological and orthographic processing in reading aloud, in silent reading, and in spelling: A four-year longitudinal study. Journal of Experimental Child Psychology, 84(3), 194-217. https://doi.org/10. 1016/S0022-0965(03)00024-9

Steinbrink, C., Knigge, J., Mannhaupt, G., Sallat, S., \& Werkle, A. (2019). Are temporal and tonal musical skills related to phonological awareness and literacy skills? - evidence from two cross-sectional studies with children from different age groups. Frontiers in Psychology, 10, 805. https://doi.org/ 10.3389/fpsyg.2019.00805

Stock, C., Marx, P., \& Schneider, W. (2017). BAKO 1-4: Basiskompetenzen für Lese-Rechtschreibleistungen. Ein Test zur Erfassung der phonologischen Bewusstheit vom ersten bis vierten Grundschuljahr (2nd ed.). Beltz.

Stuart, M. (1990). Processing strategies in a phoneme deletion task. The Quarterly Journal of Experimental Psychology, 42(2), 305-327. https://doi.org/10.1080/14640749008401224

Torgesen, J. K., Wagner, R. K., \& Rashotte, C. A. (1994). Longitudinal studies of phonological processing and reading. Journal of Learning Disabilities, 27(5), 276-286.

Treiman, R., \& Cassar, M. (1997). Can children and adults focus on sound as opposed to spelling in a phoneme counting task? Developmental Psychology, 33(5), 771-780. https://doi.org/10.1037/ 0012-1649.33.5.771

Vaknin-Nusbaum, V., Sarid, M., \& Shimron, J. (2016). Morphological awareness and reading in second and fifth grade: Evidence from Hebrew. Reading and Writing, 29(2), 229-244. https://doi.org/10. 1007/s11145-015-9587-7

Valtin, R. (1997). Strategies of Spelling and Reading of Young Children Learning German Orthography. In C. K. Leong \& R. M. Joshi (Eds.), NATO science series. Series D, Behavioural and social sciences: Vol. 87. Cross-language studies of learning to read and spell: Phonologic and orthographic processing (Vol. 160, pp. 175-193). Dordrecht London: Springer.

Varnhagen, C. K. (1995). Children's Spelling Strategies. Varieties of Orthographic Knowledge: II: Relationships to Phonology, Reading, and Writing. In V. W. Berninger (Ed.), Neuropsychology and Cognition (Vol. 11, pp. 251-290). Springer, Netherlands.

Verhoeven, L. T., \& Perfetti, C. A. (Eds.). (2017). Learning to read across languages and writing systems. Cambridge University Press.

Vernice, M., \& Pagliarini, E. (2018). Is morphological awareness a relevant predictor of reading fluency and comprehension? new evidence from Italian Monolingual and Arabic-Italian Bilingual children. Frontiers in Communication, 3, 1587. https://doi.org/10.3389/fcomm.2018.00011

Volkmer, S., Schulte-Körne, G., \& Galuschka, K. (2019). Die Rolle der morphologischen Bewusstheit bei Lese- und Rechtschreibleistungen [The role of morphological awareness in reading and spelling performance]. Zeitschrift Für Kinder-Und Jugendpsychiatrie Und Psychotherapie. https://doi. org/10.1024/1422-4917/a000652

Wilson-Fowler, E. B. (2011). Influence of morphological awareness on college student's literacy skills: A path analytic approach (Dissertation). Florida State University.

Wimmer, H., \& Goswami, U. (1994). The influence of orthographic consistency on reading development: Word recognition in English and German children. Cognition, 51(1), 91-103. https://doi.org/10. 1016/0010-0277(94)90010-8

Wimmer, H., \& Hummer, P. (1990). How German-speaking first graders read and spell: Doubts on the importance of the logographic stage. Applied Psycholinguistics, 11(04), 349. https://doi.org/10. 1017/S0142716400009620 
Wimmer, H., \& Mayringer, H. (2002). Dysfluent reading in the absence of spelling difficulties: A specific disability in regular orthographies. Journal of Educational Psychology, 94(2), 272-277. https://doi. org/10.1037//0022-0663.94.2.272

Zarić, J., Hasselhorn, M., \& Nagler, T. (2021). Orthographic knowledge predicts reading and spelling skills over and above general intelligence and phonological awareness. European Journal of Psychology of Education, 36(1), 21-43. https://doi.org/10.1007/s10212-020-00464-7

Zarić, J., \& Nagler, T. (2021). Reading comprehension on word- and sentence-level can be predicted by orthographic knowledge for German children with poor reading proficiency. Reading and Writing, 34(8), 2031-2057. https://doi.org/10.1007/s11145-021-10126-9

Ziegler, J. C., Perry, C., Jacobs, A. M., \& Braun, M. (2001). Identical words are read differently in different languages. Psychological Science, 12(5), 379-384. https://doi.org/10.1111/1467-9280.00370

Publisher's Note Springer Nature remains neutral with regard to jurisdictional claims in published maps and institutional affiliations.

\section{Authors and Affiliations}

\section{Astrid Haase $^{1,2} \mathbb{( D} \cdot$ Claudia Steinbrink $^{1}$}

1 Department of Psychology, University of Erfurt, Erfurt, Germany

2 Present Address: Department of Educational Psychology, University of Göttingen, Waldweg 26, 37073 Göttingen, Germany 